\title{
SÍNTESE DE POLÍMEROS CONDUTORES EM MATRIZES SÓLIDAS HOSPEDEIRAS
}

Daltamir J. Maia, Marco-A. De Paoli e Oswaldo L. Alves

Instituto de Química - Universidade Estadual de Campinas - CP 6154 - 13083-970 - Campinas - SP

Aldo J. G. Zarbin

Departamento de Química - Universidade Federal do Paraná - Centro Politécnico - CP 19081 - 81531-990 - Curitiba - PR

Silmara das Neves

Departamento de Química Fundamental - Instituto de Química - Universidade de São Paulo - CP 26077 - $05599-970$ - São Paulo - SP

Recebido em 7/12/98; aceito em 8/6/99

\begin{abstract}
CONDUCTIVE POLYMER SYNTHESIS IN SOLID HOST MATRICES. This review discusses the methods used to prepare conductive polymers in confined environments. This spatial restriction causes formation of defect-free polymer chains in the interlayer as porous cavities of inorganic hosts. The properties of the different composites obtained are a synergist combination of the characteristics of the inorganic host and the polymer. This opens new perspectives for the preparation of these materials and widens its potential applications.
\end{abstract}

Keywords: conductive polymers; inorganic matrices; composites.

\section{INTRODUÇÃO}

Um histórico sobre tecnologia de polímeros evidenciaria, sem dúvida alguma, que uma das propriedades mais importantes destes materiais sintéticos é a capacidade de comportar-se como excelentes isolantes elétricos, tanto para altas frequiências quanto para voltagens. No entanto, nos últimos anos uma nova classe de polímeros orgânicos tem sido desenvolvida, cuja importância está relacionada à possibilidade de conduzir eletricidade ${ }^{1}$. Os membros desta nova classe de materiais, chamados de "metais sintéticos", possuem uma característica em comum: longos sistemas $\pi$ conjugados, ou seja, uma alternância de ligações simples e duplas ao longo da cadeia. O interesse evidente é combinar em um mesmo material as propriedades elétricas de um semicondutor ou metal com as vantagens de um polímero.

Desde a década de 60, é conhecido que moléculas orgânicas que apresentam duplas ligações conjugadas podem exibir propriedades semicondutoras. $\mathrm{O}$ desenvolvimento inicial foi inibido pelo fato que as cadeias rígidas, em uma estrutura conjugada, também produzem uma intratabilidade extrema, tal que a maioria dos primeiros exemplos de polímeros condutores eram infusíveis, insolúveis e, portanto, de pouco valor tecnológico. No começo dos anos 70 Shirakawa e Ikeda $^{2,3}$ demonstraram a possibilidade de preparar filmes auto-suportados de poliacetileno pela polimerização direta do acetileno. O polímero produzido apresentou propriedades semicondutoras que atraiu pouco interesse até 1977, quando MacDiarmid e cols. ${ }^{4}$ descobriram que, tratando o poliacetileno com ácido ou base de Lewis, era possível aumentar a condutividade em até 13 ordens de grandeza. Este processo envolve a remoção ou adição de elétrons da cadeia polimérica, sendo denominado "dopagem". O termo dopagem é utilizado em analogia com os semicondutores inorgânicos cristalinos, sugerindo semelhanças com os polímeros intrinsecamente condutores (PICs). Em ambos os casos a dopagem é aleatória e não altera a estrutura do material. No entanto, na dopagem de um polímero as impurezas não são introduzidas nas cadeias, mas sim nas suas "vizinhanças". A interação impureza-cadeia gera deformações e "defeitos carregados" localizados, responsáveis pelo aumento na condutividade ${ }^{5}$. Outra diferença significativa está na quantidade de dopante

e-mail: mdepaoli@iqm.unicamp.br utilizada. Enquanto os semicondutores apresentam "impurezas" que atuam como dopantes, da ordem de ppm, os PICs chegam a ter $50 \%$ em massa de dopantes.

Desde a publicação do trabalho de MacDiarmid e cols ${ }^{4}$, houve um crescimento significativo da pesquisa sobre estruturas poliméricas conjugadas, levando ao desenvolvimento de novas famílias de polímeros condutores. Com modificações químicas apropriadas, eles podem exibir um intervalo de condutividades desde semicondutor até condutor, chegando a condutividades comparáveis à do cobre $\left(10^{6} \mathrm{~S} . \mathrm{cm}^{-1}\right)$. Dentre as famílias mais estudadas citamos: poliacetileno, polianilina, polipirrol e politiofeno; cujas estruturas, nas formas reduzidas e não dopadas estão representadas na Figura 1.

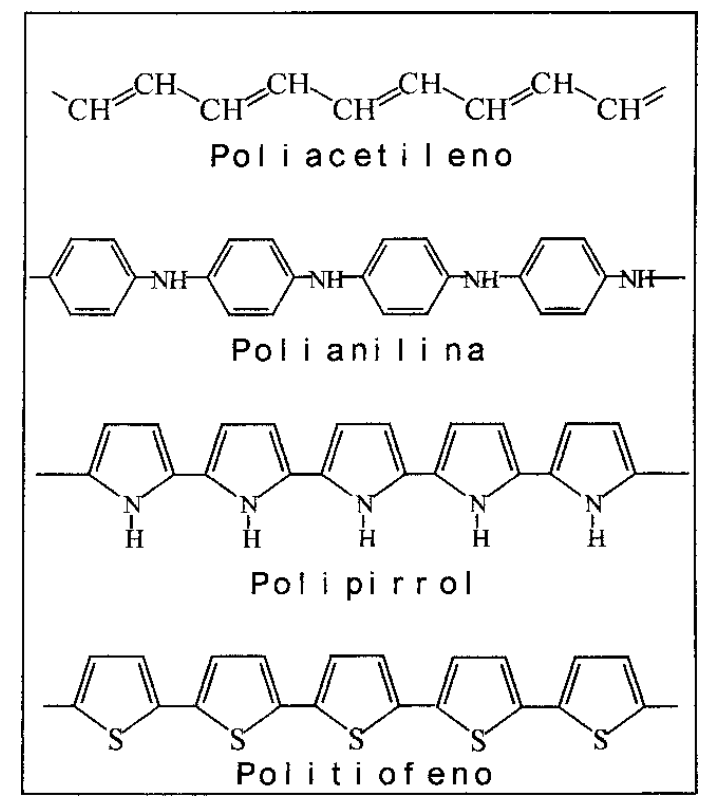

Figura 1. Estruturas dos polímeros condutores intrínsecos (PICs) mais estudados.

A obtenção dos polímeros condutores, com exceção do poliacetileno, é bastante simples, sendo o método eletroquímico 
o mais relatado ${ }^{6}$. A eletropolimerização tem estequiometria eletroquímica entre 2,2 e 2,6 F.mol ${ }^{-1}$, dependendo do polímero e das condições de síntese ${ }^{7}$. No processo de polimerização são consumidos 2,0 F.mol ${ }^{-1}$ e a carga excedente é usada no processo de dopagem do polímero, o qual ocorre simultaneamente à síntese. O mecanismo de eletropolimerização para heterocícliclos considera a formação de um cátion-radical do monômero, seguida do acoplamento de dois cátions radicais, com saída de dois prótons e reconstituição do sistema aromático ${ }^{7}$. A reação continua com o acoplamento de cátions radicais do monômero e cátions radicais dos oligômeros formados.

A estabilidade do cátion radical do monômero é o fator determinante para obtenção de um polímero com elevado grau de conjugação. Um cátion radical muito estável pode difundir do eletrodo dando origem a oligômeros solúveis, enquanto que um muito reativo, pode sofrer reações colaterais. As propriedades elétricas e físico-químicas do material eletrossintetizado dependem fortemente das condições de síntese, tais como: concentração do monômero, natureza do meio eletrolítico, temperatura, etc ${ }^{6,8,9}$.

Os polímeros condutores podem também ser obtidos por síntese química ${ }^{10}$. Neste caso, um agente oxidante é introduzido no meio reacional provocando a formação do cátion radical. A princípio, o requisito básico para a espécie ser utilizada como oxidante é possuir um potencial de redução suficiente para a oxidação do monômero.

Inúmeras aplicações tecnológicas têm sido propostas e desenvolvidas para polímeros condutores baseando-se, principalmente ${ }^{11}$ :

$i$. na condutividade do polímero condutor puro ou de uma blenda do polímero condutor com um polímero convencional (aplicação em diodos emissores de luz ${ }^{12-18}$, filmes para dissipação de carga estática ${ }^{19,20}$, blindagem eletromagnética ${ }^{21-23}$ );

ii. nas propriedades eletroquímicas de oxi-redução do polímero (janelas eletrocrômicas ${ }^{24,25}$, capacitores ${ }^{10,26}$, dispositivos para armazenamento de energia ${ }^{27-30}$, músculos artificiais ${ }^{31}$ );

iii. na formação de estados excitados no polímero (componente de dispositivos para óptica não-linear $\left.{ }^{32-34}\right)$;

$i v$. na morfologia/microestrutura do polímero (sensores quími$\cos ^{35-37}$, catálise ${ }^{38,39}$ )

A Figura 2 ilustra algumas aplicações conhecidas e outras propostas para os polímeros condutores, em função das suas propriedades ${ }^{10}$.

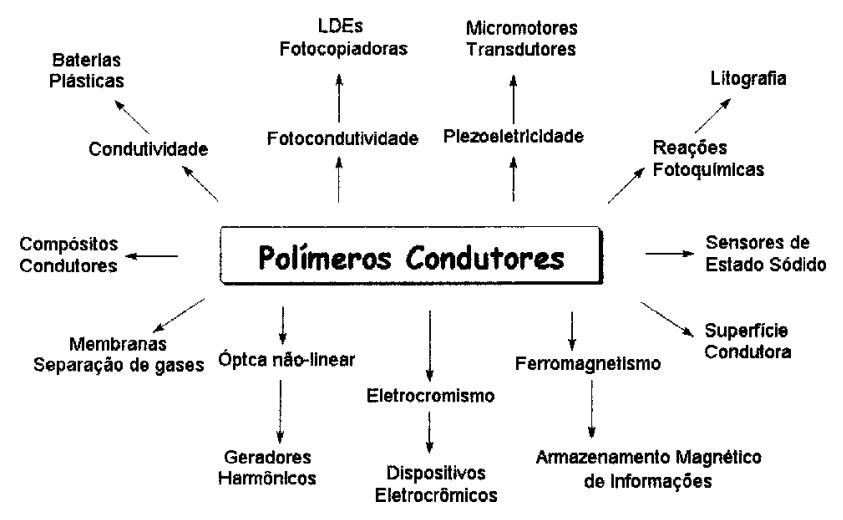

Figura 2. Esquema mostrando várias aplicações conhecidas e propostas para polímeros condutores, em função das suas propriedades.

Todavia, as propriedades destes polímeros são fortemente dependentes de sua microestrutura e morfologia as quais estão relacionadas à presença de defeitos, reticulações, entre outros fatores, sendo determinadas pelo método de síntese, contraíons e outras variáveis difíceis de serem controladas simultaneamente. Um dos maiores desafios para melhorar e garantir a performance destes materiais consiste, por conseguinte, na busca de polímeros com maior homogeneidade, estabilidade, baixa concentração de defeitos, maior organização entre as cadeias, reprodutibilidade e maiores valores de condutividade.

$\mathrm{O}$ mecanismo através do qual os polímeros conduzem eletricidade tem sido apresentado detalhadamente na literatura ${ }^{40,41}$. A consideração mais importante do ponto de vista químico e também foco desta revisão considera que "um aumento da condutividade eletrônica é obtido quando são preparados polímeros com maior ordenamento molecular e supermolecu-

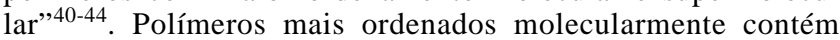
poucos defeitos que interrompem a conjugação da cadeia polimérica, como p. ex. carbonos com hibridização $\mathrm{sp}^{3}$. Em polímeros com elevada ordem supermolecular, as cadeias são ordenadas através de estiramentos e/ou cristalização. Com base nestas considerações, condutividades de até $10^{5} \mathrm{~S}_{\mathrm{cm}} \mathrm{cm}^{-1}$ foram determinadas para o poliacetileno altamente ordenado ${ }^{45}$, aproximando-se, portanto, da condutividade do cobre à temperatura ambiente. Infelizmente, as formas "dopadas" do poliacetileno são tão reativas que impossibilitam a sua utilização na maioria das aplicações propostas para polímeros condutores ${ }^{46}$. Assim, como a condutividade de materiais quimicamente estáveis (como p. ex., polianilina, polipirrol e politiofeno), é algumas ordens de grandeza mais baixa, o desenvolvimento de estratégias que viabilizem o aumento da condutividade desses polímeros tem sido o objetivo de muitas pesquisas.

Uma das possibilidades mais promissoras para obtenção de polímeros condutores com condutividade elevada consiste no "encapsulamento" das cadeias poliméricas no interior de espaços vazios de estruturas hospedeiras (poros, lamelas, cavidades), através da polimerização in situ no interior de tais espaços. Sob este enfoque R-Hitzky e Aranda ${ }^{47}$ descreveram recentemente alguns processos de inclusão de polímeros em matrizes hospedeiras (principalmente lamelares e zeólitas) para preparação de compósitos com alto grau de agregação de cadeias poliméricas que resultam em materiais com elevada condutividade.

Um dos métodos mais explorados nas últimas décadas, conhecido como "síntese template", foi relatado pela primeira vez em 1949 por Dickey ${ }^{48}$. Recebeu esta denominação porque os espaços vazios da matriz são utilizados como molde e determinam a forma, o tamanho e, em alguns casos, a orientação do material sintetizado no seu interior. A Figura 3 ilustra esse processo de síntese ${ }^{49}$.

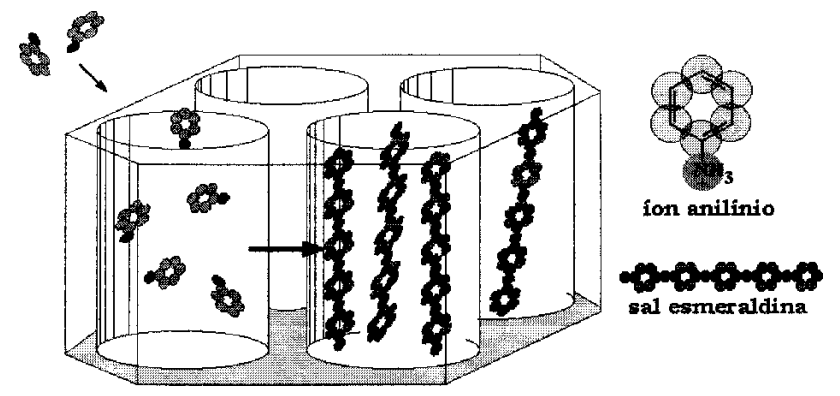

Figura 3. Esquema ilustrativo da síntese template da polianilina em matriz unidimensional.

Através da síntese template têm-se obtido polímeros condutores $^{22-24}$, metais ${ }^{20,22,25}$, semicondutores ${ }^{26}$, $\operatorname{carbonos}^{27,28}$ e outros materiais, em escala nanométrica ${ }^{50}$. $\mathrm{Na}$ área de síntese template de polímeros condutores, Martin e cols. ${ }^{51-53}$ têm concentrado esforços na obtenção de polipirrol, poli (3metiltiofeno) e/ou polianilina sintetizados química ou eletroquimicamente no interior dos poros de membranas. Tais autores observaram que ocorre nucleação e crescimento dos polímeros, preferencialmente na parede dos poros da membrana. Consequentemente, após curtos períodos de polimerização obtêm-se verdadeiros "tubos poliméricos". Existe uma série de 
aplicações propostas para estruturas tubulares desse tipo, destacando-se sua utilização na imobilização de enzimas ${ }^{53,54}$. Dessa forma, através do controle do tempo de polimerização, podese obter polímeros condutores na forma de tubos ou filamentos (longo tempo de polimerização) com condutividades algumas ordens de grandeza maiores em relação às formas convencionais do mesmo polímero (filmes finos ou pó) ${ }^{29-34}$.

Compósitos ou nanocompósitos são obtidos, no caso, em que a matriz utilizada na síntese não é dissolvida pois, as dimensões da fase polimérica sintetizada estarão delimitadas pelas dimensões dos espaços vazios das matrizes hospedeiras, geralmente na faixa de nanômetros. Os (nano) compósitos são materiais muitos interessantes, pois apresentam comportamento sinergístico do polímero e a matriz, com propriedades que diferem daquelas de seus componentes individuais ${ }^{55,56}$. Utilizando-se matrizes template inorgânicas os (nano) compósitos obtidos possuirão características híbridas, podendo apresentar melhores propriedades mecânicas, térmicas, químicas, elétricas, entre outras. $O$ interesse particular na investigação de materiais (nano) compósitos pode ser constatado na literatura onde observa-se um significativo aumento no número de publicações nesta área nos últimos anos ${ }^{57-65}$.

Assim o método template consiste em reações do tipo hospedeiro/convidado onde o convidado (guest) é sintetizado em um hospedeiro (host) com tamanho e forma de poros controlados, possibilitando a organização e estabilização de materiais, em micro e nanoescala, sem provocar modificações substanciais na estrutura do hospedeiro. A estratégia para utilização desse método envolve uma seleção criteriosa do hospedeiro ou matriz bem como uma escolha conveniente do material a ser sintetizado no seu interior. São descritos vários materiais que podem ser utilizados como hospedeiros ${ }^{66}$. Eles podem ser inorgânicos, orgânicos ou organometálicos, com estruturas unidimensional (filamento: grafite, zeólitas, membranas Nuclepore, etc. $)^{49,67}$, bidimensional (lamelas: grafite, filmes inorgânicos LangmuirBlodgett, camadas de óxidos, haletos, calcogenetos, fosfatos de metais tetravalentes, etc. ${ }^{68-71}$ ou tridimensional (vidros porosos, zeólitas, complexos buckiball, membranas porosas, etc. $)^{72,73}$. Os espaços vazios destes hospedeiros podem variar de tamanho, distância de separação, perfeição e homogeneidade. São encontrados hospedeiros que possuem canais cujas dimensões variam de 5 a $10^{4} \AA$, espaços interlamelares variam de 3 a $50 \AA$ e os diâmetros de cavidade de 6 a $10^{4} \AA^{66}$. Os hospedeiros podem ser ainda do tipo isolante, semicondutor, metálico ou supercondutor. Tais hospedeiros podem adquirir esse caráter após a inclusão do convidado. A Figura 4 ilustra a diversidade de hospedeiros para síntese template.
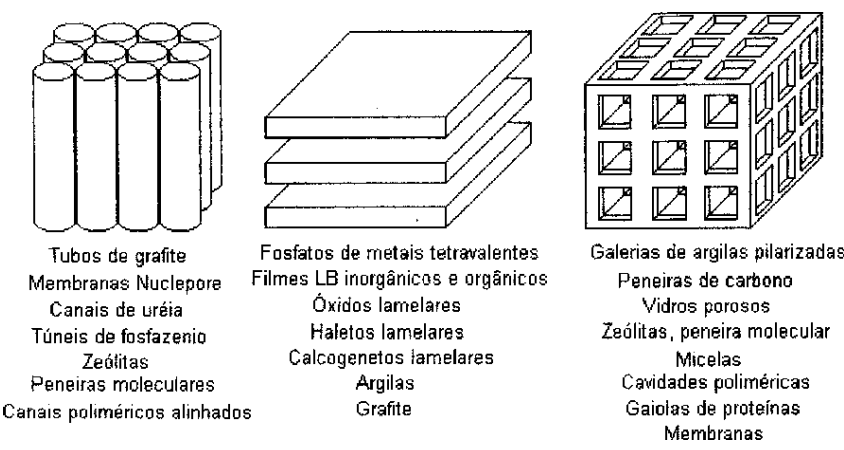

Figura 4. Exemplos de matrizes hospedeiras que podem ser utilizadas na síntese template: a) matrizes unidimensionais (filamentos), b) matrizes bidimensionais (lamelas), c) matrizes tridimensionais (redes).

A mesma diversidade é encontrada na escolha do convidado. Neste sentido, a proposta desta revisão é fornecer, através de exemplos de sistemas desenvolvidos em nossos laboratórios e de um levantamento bibliográfico atual, o "estado-da-arte" de materiais (nano) compósitos obtidos a partir da síntese de polímeros condutores no interior de matrizes sólidas hospedeiras.

\section{POLÍMEROS CONDUTORES}

Embora o poliacetileno, $(\mathrm{CH}) \mathrm{x}$, tenha sido o primeiro polímero condutor sintetizado ${ }^{74}$, devido à sua instabilidade térmica e ambiental, outros polímeros passaram a ser intensivamente investigados com o intuito de superar estas limitações. Assim, os polímeros heterocíclicos, dentre eles o polipirrol (PPi), politiofeno (PTf) e polianilina (PAni) e seus derivados são os mais estudados. Apesar desses materiais serem conhecidos há muito tempo (PAni - $1862^{75}$, PTf $-1883^{76}$ e PPi $1916^{77}$ ), uma "redescoberta" se deu no final da década de 70 , após o trabalho pioneiro dos grupos de Shirakawa, MacDiarmid e Heeger, relatando a condutividade metálica do poliacetileno dopado com iodo ${ }^{4}$.

A polianilina e os polímeros derivados da anilina são, sem dúvida, os polímeros condutores que têm recebido maior atenção nos últimos anos devido principalmente, à estabilidade química de sua forma condutora em condições ambientais, facilidade de polimerização e dopagem e baixo custo do monômero. A PAni pode ser sintetizada através de oxidação química ou eletroquímica da anilina em meio ácido. O método de síntese geralmente é escolhido em função da aplicação a que o polímero se destina ${ }^{78}$. Independentemente do método de síntese, sua composição química na forma de base (não dopada) é representada por uma estrutura geral ${ }^{79,80}$ formada por $y$ e $(1-y)$ unidades repetitivas das espécies reduzida e oxidada, respectivamente (Figura 5).

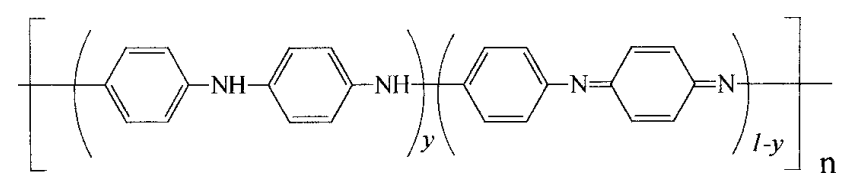

Figura 5. Estrutura da polianilina na forma de base (não dopada).

A princípio, y pode variar de 0 até 1 , mas duas formas extremas e uma forma intermediária são usualmente diferenciadas na literatura $^{81}$ : a forma totalmente reduzida $(\mathrm{y}=1)$, conhecida por leucoesmeraldina; a forma totalmente oxidada $(\mathrm{y}=0)$, a pernigranilina, e a forma parcialmente oxidada $(\mathrm{y}=0,5)$, esmeraldina. Esta fórmula geral mostra somente as formas básicas do polímero. No entanto, a PAni pode ser dopada por protonação, isto é, sem que ocorra alteração no número de elétrons associados à cadeia polimérica. Logo, os nitrogênios imínicos e amínicos destas espécies podem estar total ou parcialmente protonados, dependendo do $\mathrm{pH}$ da solução ao qual o polímero foi exposto, obtendo-se o polímero na forma de sal (forma dopada). O sal esmeraldina é a forma estrutural onde a PAni alcança os maiores valores de condutividade ${ }^{82}$. Através de reações de oxidação e redução, bem como de tratamentos com ácidos e bases, é possível converter reversivelmente, a PAni em suas diferentes formas, o que confere a este polímero um grande potencial de aplicações tecnológicas ${ }^{83}$.

Pirrol, tiofeno e seus derivados também são facilmente oxidados eletroquimicamente. Esta rota de síntese tem sido preferencialmente utilizada por permitir a formação de filmes finos sobre eletrodos. A polimerização eletroquímica desses monômeros é bastante similar e tem sido reportada por muitos autores, entre eles Tourillon e Garnier ${ }^{84-86}$ e Kaneto e cols. ${ }^{87,88}$.

Para o PPi, o crescimento ideal das cadeias consiste em acoplamentos nas posições 2 e 5 dos átomos de carbono do anel pirrólico, situação onde a conjugação entre as ligações duplas e simples é maximizada. Contudo, um grande número de acoplamentos em outros átomos de carbono do anel é verificado, diminuindo a mobilidade dos portadores de carga. 
Estima-se que cerca de $30 \%$ das ligações C-C entre os anéis pirrólicos não são do tipo ideal $2,5^{1}$. Uma representação esquemática dos vários tipos de defeitos possíveis de serem encontrados no PPi é apresentado na Figura 6.

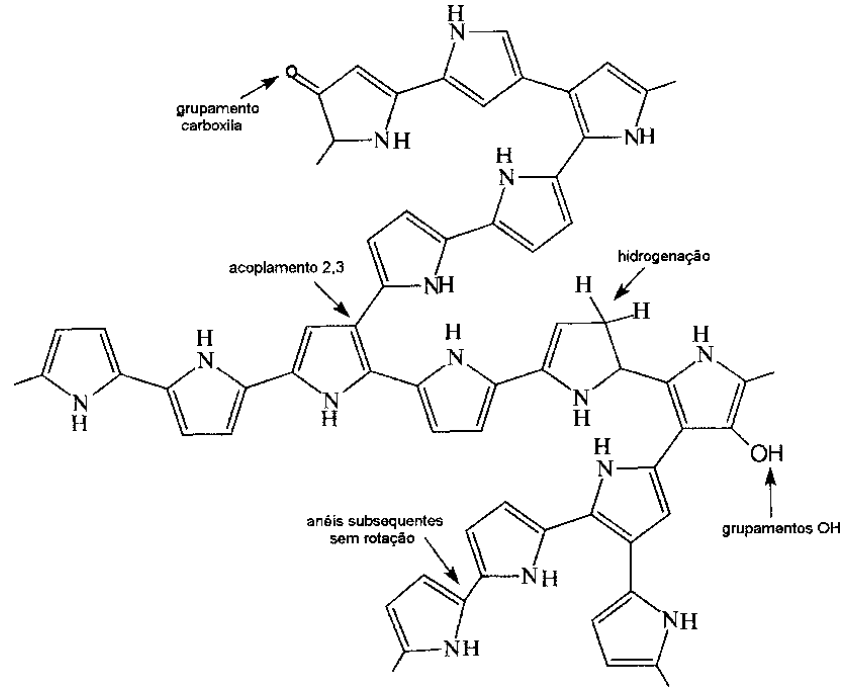

Figura 6. Ilustração dos possíveis defeitos estruturais apresentados pelo polipirrol.

Sabe-se que a condutividade em um sólido é causada por dois fatores: o número de portadores de carga (elétrons/buracos) e a mobilidade destes portadores. A condutividade elétrica de muitos polímeros condutores está na mesma faixa de grandeza da maioria dos semicondutores inorgânicos ${ }^{89}$, como pode-se observar na Figura 7. Os semicondutores inorgânicos possuem um baixo número de portadores (na ordem de $10^{16}$ a $10^{18} \mathrm{~cm}^{-3}$ ), mas possuem altas mobilidades $\left(10^{2}\right.$ a $\left.10^{5} \mathrm{~cm}^{2} \cdot \mathrm{V}^{-1} \cdot \mathrm{s}^{-1}\right)$. Esta alta mobilidade é devida ao alto grau de cristalinidade e pureza destes materiais, bem como ao número relativamente baixo de defeitos presentes na sua estrutura ${ }^{1}$. Os polímeros condutores, por outro lado, possuem um grande número de portadores $\left(10^{21}\right.$ a $\left.10^{23} \mathrm{~cm}^{-3}\right)$, mas uma baixíssima mobilidade $\left(10^{-4}\right.$ a $\left.10^{-5} \mathrm{~cm}^{2} . \mathrm{V}^{-1} \cdot \mathrm{s}^{-1}\right)$ devido, principalmente, ao grande número de defeitos estruturais (reticulação e desordenamento das cadeias), como exemplificado para o polipirrol na Figura 6.

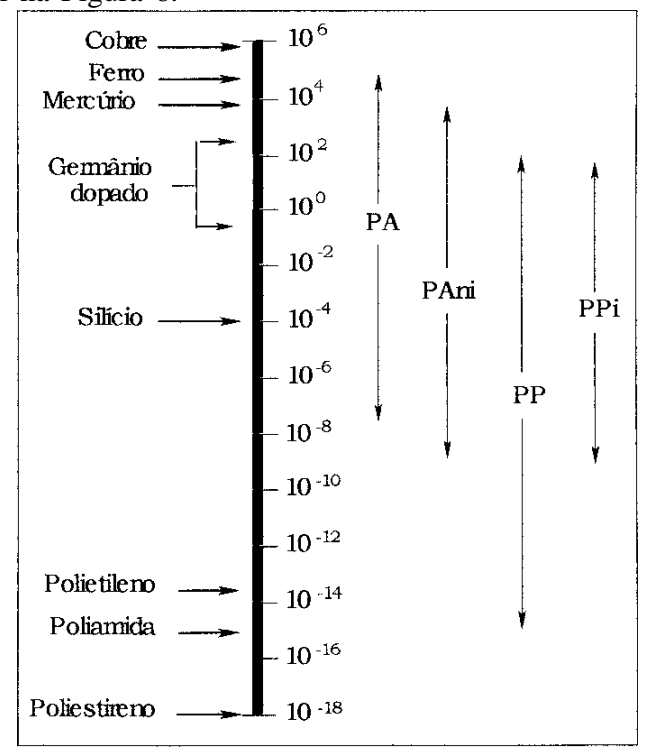

Figura 7. Comparação da condutividade dos PICs com alguns materiais. $P A=$ Poliacetileno, $P A n i=$ Polianilina,$P P=P o l i(p-$ fenileno $)$ e PPi $=$ Polipirrol.
Desta maneira, a obtenção de polímeros condutores com maiores condutividades está diretamente relacionada ao aumento da mobilidade dos portadores. Isto pode ser viabilizado através da obtenção de materiais mais ordenados, ou seja, com melhor orientação das cadeias, livre de reticulações e defeitos. Vários métodos têm sido propostos na literatura com esta finalidade $^{1,80}$, p. ex., passando-se uma solução de politiofeno por um campo magnético, e extraindo-se o solvente, para garantir um alto grau de alinhamento das cadeias.

Todavia, como já mencionado na Introdução, um dos métodos mais promissores na obtenção de polímeros condutores com orientação preferencial e um baixo número de defeitos estruturais consiste em crescê-los em espaços limitados, presentes em matrizes sólidas hospedeiras. A matriz hospedeira deve propiciar um ambiente restrito, que obrigue o polímero a orientar-se e impeça as reticulações. Neste sentido, várias matrizes, com diferentes características, têm sido reportadas na formação de (nano) compósitos com polímeros condutores. Uma descrição dos principais resultados relatados na literatura é apresentada a seguir.

\section{MATRIZES HOSPEDEIRAS UNIDIMENSIONAIS}

A síntese em nanoescala de fibras, cilindros e fios de polímeros condutores tem despertado um grande interesse em diversas áreas da comunidade científica, principalmente ligadas à química, biologia, física e ciência dos materiais ${ }^{53,90}$. Cada uma dessas áreas com enfoques diferentes mas, envolvidas na interdisciplinaridade do tema, visam explorar as potencialidades desses materiais, obedecendo orientações bem determinadas. $\mathrm{O}$ isolamento de moléculas individuais de polímeros condutores abre uma grande perspectiva para sua utilização como componente integral, ou seja, "fios moleculares", em dispositivos eletrônicos moleculares. Este conceito baseia-se no fato de que circuitos eletrônicos mais rápidos e menores só poderão ser obtidos com a utilização de moléculas individuais como elementos lógicos de chaveamento e amplificação, sendo os polímeros condutores fortes candidatos a este propósito $^{91-93}$. Assim, as aplicações vão desde dispositivos eletrônicos, ópticos e mecânicos ${ }^{94-97}$ até bioencapsulamento ${ }^{98,99}$ e liberação controlada de medicamentos ${ }^{100,101}$. Na grande maioria das publicações, os "fios de polímeros condutores" são obtidos, utilizando-se como matriz template 1-D, dois tipos de membranas: membranas track etch e aluminas porosas.

As membranas track etch são disponíveis comercialmente (Poretics, Nuclepore - membrana a base de policarbonato) com vários tamanhos de poros a partir de $10 \mathrm{~nm}$ e com densidade de aproximadamente $10^{9}$ poros. $\mathrm{cm}^{-2} 54,102$. Seu processo de fabricação envolve uma etapa inicial de irradiação de filmes densos de policarbonato ou poliéster por partículas $\alpha$. As partículas atravessam o filme quebrando ligações da cadeia polimérica. A seguir, o filme sofre um lixiviamento químico. $\mathrm{O}$ ataque ocorre preferencialmente nas regiões atravessadas pelas partículas e o diâmetro dos poros aumenta com o tempo de imersão no banho de lixiviamento ${ }^{103,104}$.

As membranas de alumina porosa são preparadas eletroquimicamente a partir de alumínio metálico ${ }^{105}$. Densidades de poros tão elevadas quanto $10^{11}$ poros. $\mathrm{cm}^{-2}$ podem ser encontradas, porém, somente um número limitado de diâmetros estão disponíveis comercialmente (Anopore) ${ }^{106}$. A vantagem de utilização das membranas de alumina em relação às track etch na síntese template está relacionada à densidade de poros. As membranas de alumina possuem cerca de $65 \%$ de poros enquanto que a porosidade das membranas Nuclepore é de, aproximadamente, $15 \%$. Assim, uma quantidade maior de "tubos" ou "filamentos" por área de matéria-prima (membrana) pode ser preparada a partir de membranas de alumina. Isto pode ser importante do ponto de vista de aplicações comerciais.

Apesar de menos comuns, outros materiais nanoporosos têm sido utilizados como hospedeiros 1-D. Tonucci e cols. ${ }^{107}$ 
descreveram um vidro com nanocanais de $33 \mathrm{~nm}$ de diâmetro e densidade igual a $3 \times 10^{10}$ poros. $\mathrm{cm}^{-2}$. Beck e cols. ${ }^{108}$ prepararam a xeolita com diâmetro de poros maiores. Douglas e cols. ${ }^{109}$ demonstraram que poros com diâmetros da ordem de nanômetros numa proteína derivada de bactérias, podem ser usados para transferir a imagem desses poros para outro substrato.

Para que os polímeros condutores possam ser sintetizados eletroquimicamente no interior dos poros desses materiais é necessário, inicialmente, que uma das superfícies da membrana seja recoberta com filme metálico, para utilizá-la como eletrodo de trabalho. No caso da síntese química é utilizado um aparato experimental conforme ilustrado na Figura $8^{53}$. O monômero é separado da solução do agente oxidante pela membrana porosa. Ambos (monômero e agente oxidante) difundem-se através dos poros da membrana reagindo no seu interior.

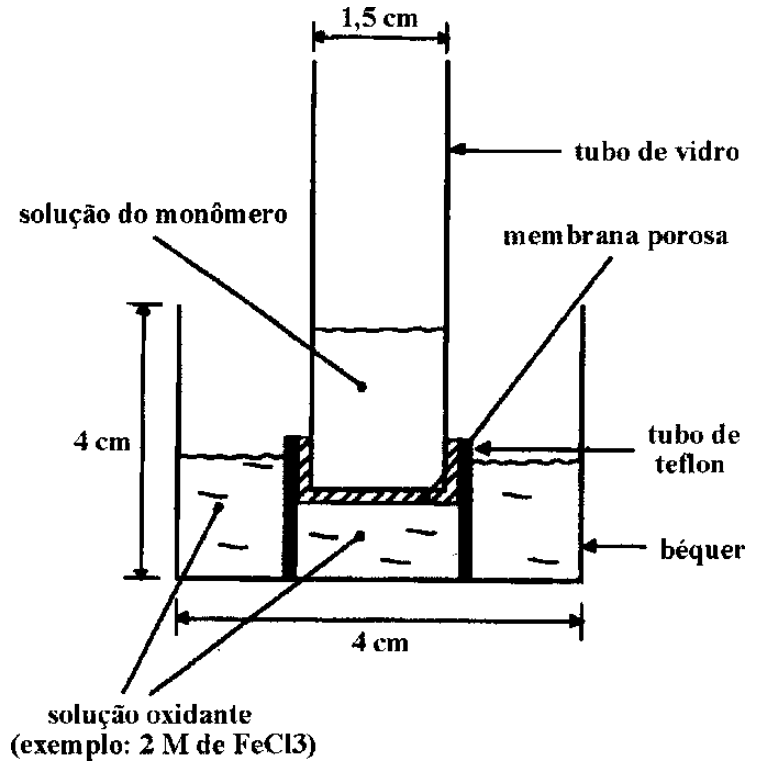

Figura 8. Esquema experimental da síntese química do polipirrol nos poros da membrana Nuclepore ${ }^{53}$.

Tanto na síntese química como eletroquímica, controlando o tempo de polimerização, obtém-se tubos ou filamentos do polímero condutor. No entanto, em contraste com o polipirrol e o poli (3-metiltiofeno), os tubos de polianilina nunca se fecham mesmo após um longo tempo de polimerização ${ }^{110}$. Além do interesse nos compósitos e nanocompósitos formados entre a membrana e os polímeros condutores, pode-se ainda recuperar o polímero isoladamente da membrana, dissolvendo-se esta em um solvente apropriado (no qual o polímero seja insolúvel), e coletando-se o polímero por filtração. As cadeias de polímeros obtidas após este tratamento são várias ordens de grandeza mais condutoras que os respectivos polímeros obtidos de maneira convencional.

$\mathrm{O}$ aumento da condutividade dos polímeros sintetizados via template, tem sido verificado pelos métodos de duas $5^{51,90}$ e quatro pontas ${ }^{110,111}$. A Figura 9 ilustra os resultados obtidos com o polipirrol sintetizado em membranas com diversos diâmetros de poros ${ }^{112}$. Observa-se claramente que os filamentos de polipirrol com maiores diâmetros apresentam condutividade comparáveis as do bulk das amostras de polipirrol sintetizadas convencionalmente. Por outro lado, com a diminuição do diâmetro dos filamentos constatou-se o aumento da condutividade em uma ordem de grandeza. O mesmo comportamento foi verificado com a polianilina ${ }^{110,111}$ e o poli (3-metiltiofeno) ${ }^{51}$ e é atribuído ao alinhamento das cadeias obtidas via template. Este maior ordenamento tem sido comprovado principalmente através da técnica de espectroscopia de absorção de infravermelho polarizado (Polarized Infrared Absorption Spectroscopy - PIRAS) ${ }^{90,113-114}$.
O método PIRAS é baseado em medidas da absorção, de dois feixes de radiação infravermelho polarizados ortogonalmente por uma amostra polimérica. Esses dados de absorção são usados para calcular a razão dicróica, R, da amostra polimérica. Um valor de $\mathrm{R}$ igual à unidade indica que as cadeias poliméricas não apresentam orientação espacial preferencial. Contrariamente, quanto menores os valores de $\mathrm{R}$ maior a extensão de alinhamento das cadeias.

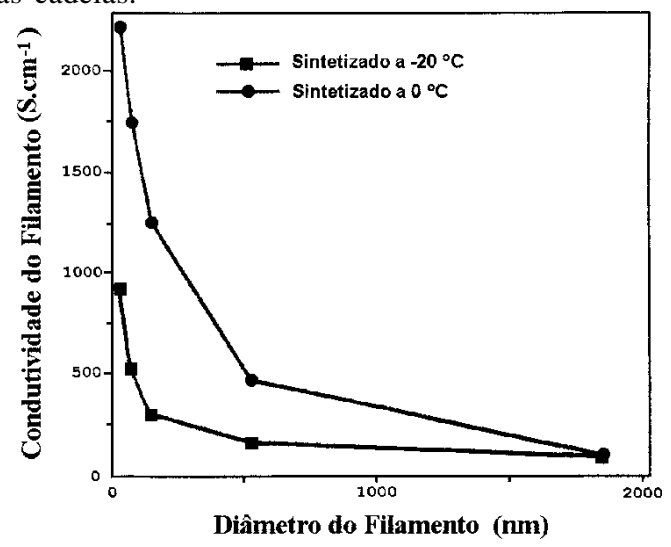

Figura 9. Condutividade versus diâmetro dos filamentos de polipirrol. Resultados para as sínteses realizadas a $0{ }^{\circ} \mathrm{C} e-20{ }^{\circ} \mathrm{C}^{112}$.

A variação do tempo de polimerização na síntese template também tem sido investigada pelo método PIRAS. A Figura 10 ilustra os resultados obtidos com a polianilina sintetizada em membrana Nuclepore ${ }^{110}$. Através do controle do tempo de polimerização é possível controlar a espessura das paredes dos tubos de polímeros formados no interior dos poros da membrana template. Assim, os resultados apresentados na Figura 10 demonstram que a camada de polianilina depositada diretamente nas paredes dos poros é a mais ordenada (menor razão dicróica) mas que este ordenamento diminui a medida que outras camadas de polímero são depositadas (razão dicróica aumenta com o tempo de polimerização). Resultados semelhantes foram obtidos com tubos de polipirrol ${ }^{115}$. A primeira camada de polímero condutor é a mais ordenada porque segue o ordenamento das cadeias que formam as paredes internas dos poros da membrana hospedeira. Tal ordenamento, imposto pelo hospedeiro, é perdido após subseqüentes deposições de camadas poliméricas, razão pela qual a parte central dos filamentos é menos orientada. Um efeito similar tem sido observado quando o polipirrol é depositado eletroquimicamente sobre a superfície de um eletrodo ${ }^{116}$. Consequentemente, os maiores valores de condutividade foram registrados com filamentos de menor diâmetro, uma vez que eles contêm uma proporção relativamente maior de material ordenado ${ }^{117}$.

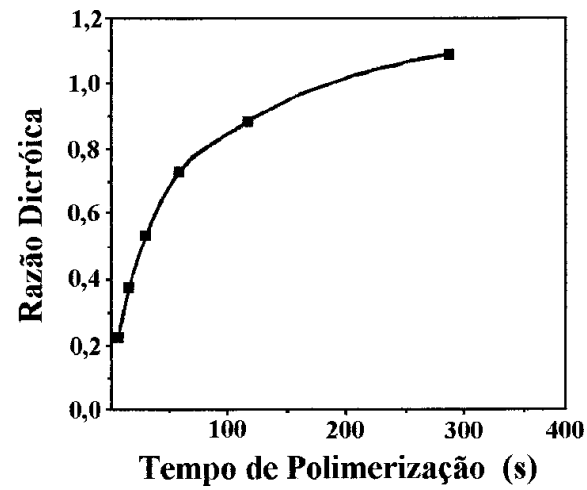

Figura 10. Variação da razão dicróica, determinada pela espectroscopia de absorção de Infravermelho polarizada (PIRAS), em função do tempo de polimerização da polianilina. $O$ eixo x pode ser considerado como o eixo da espessura das paredes ${ }^{110}$. 
Também é descrito na literatura a obtenção de fios de PAni encapsulados em hospedeiros alumino-silicatos conhecidos como MCM-41 ${ }^{118}$. Desde sua descoberta em 1992, o MCM-41 tornou-se o membro mais popular da família M41S de materiais mesoporosos de silicatos e alumino-silicatos ${ }^{119,120}$. O MCM41 possui um sistema regular de poros que consiste em um arranjo unidimensional de poros hexagonais com estreita distribuição de tamanho. As paredes dos poros são compostas de sílica amorfa, conforme determinado por medidas de difratometria de raios-X $(\mathrm{DRX})^{119}$. A microscopia eletrônica de transmissão sugere que a espessura das paredes dos poros seja de aproximadamente $1 \mathrm{~nm}^{121}$. O tamanho dos poros pode ser ajustado entre 2 e $8 \mathrm{~nm}$ durante a síntese, através da adição de surfactantes com diferentes comprimentos de cadeias ou de auxiliares orgânicos como 1,3,5-trimetilbenzeno. Grandes áreas de superfície específica (de até $1500 \mathrm{~m}^{2} \cdot \mathrm{g}^{-1}$ ) têm sido obtidas. Devido a esta estrutura regular de poros e estreita distribuição de tamanho, o MCM-41 é usado em várias aplicações, principalmente, em cromatografia ${ }^{122,123}$, catálise $\mathrm{e}^{124} \mathrm{e}$, mais recentemente, como matriz template na síntese de polímeros condutores e outros materiais ${ }^{125}$.

\section{MATRIZES HOSPEDEIRAS BIDIMENSIONAIS}

Polímeros condutores (principalmente a polianilina) já foram preparados em diversas matrizes lamelares, tais como: $\mathrm{FeOCl}^{70,126}, \mathrm{~V}_{2} \mathrm{O}_{5}{ }^{127,128}, \mathrm{MoO}_{3}{ }^{71}$, fosfato de uranila ${ }^{68}$, aluminosilicatos e $\operatorname{argilas}^{129}$. Em tais compostos as lamelas estão ligadas entre si por forças de Van der Waals, ligações iônicas ou até mesmo de caráter metálico ${ }^{130}$. Nestes, as forças interlamelares são bem mais fracas que as forças intralamelares de natureza covalente. Tal situação possibilita a entrada de íons ou moléculas no espaço interlamelar através da expansão da direção normal aos planos lamelares da matriz hospedeira, com variações que podem alcançar $50 \AA$ sem destruição do arranjo lamelar, via um processo conhecido como intercalação ${ }^{131}$

Em 1987 Kanatzidis e cols. ${ }^{132}$ descreveram o primeiro exemplo de obtenção de um polímero condutor no interior do espaço lamelar de um material bidimensional. Estes autores polimerizaram o pirrol no interior das lamelas do $\mathrm{FeOCl}$ (estrutura lamelar representada na Figura 11), formando um composto cuja estequiometria poderia ser representada por $(\mathrm{PPi})_{0,34} \mathrm{FeOCl}$. A reação foi realizada entre o $\mathrm{FeOCl}$ e o pirrol puro, ocorrendo a polimerização via redução dos átomos de $\mathrm{Fe}^{3+}$ da matriz. Devido à presença do polímero determinou-se um aumento na distância interlamelar de 7,98 para $13,21 \AA$. Estes mesmos autores também investigaram a polimerização do tiofeno ${ }^{133}$ e da anilina ${ }^{134}$ em FeOCl. No caso do nanocompósito polianilina/ $\mathrm{FeOCl}$, a síntese foi realizada através da agitação de $\mathrm{FeOCl}$ com uma solução $5 \%$ de anilina em acetonitrila, por uma semana ${ }^{134}$. Foi observado um aumento de $5,94 \AA$ na distância interlamelar do $\mathrm{FeOCl}$ após a polimerização, distância suficiente para acomodar uma única camada do polímero. Os autores observaram que o polímero formado neste nanocompósito apresenta restrições de movimento devido ao ambiente confinado em que suas moléculas se encontram. Concluíram também que, as cadeias formadas no espaço interlamelar do $\mathrm{FeOCl}$ são mais curtas que aquelas obtidas convencionalmente ${ }^{134}$.

Usando método semelhante a polianilina também foi intercalada em $\mathrm{V}_{2} \mathrm{O}_{5}{ }^{128,135} \mathrm{WO}_{3}{ }^{136}, \mathrm{MoO}_{3}{ }^{71,137}, \mathrm{Zr}\left(\mathrm{HPO}_{4}\right)_{2}{ }^{138}$, $\mathrm{VOPO}_{4}{ }^{139}, \mathrm{HUO}_{2} \mathrm{PO}_{4}{ }^{68}$, hidróxidos duplos lamelares ${ }^{140}$ e' $\mathrm{MoS}_{2}{ }^{141}$. O método de obtenção do polímero em cada um destes nanocompósitos varia ligeiramente de acordo com as características da matriz utilizada. Por exemplo, matrizes que contêm espécies altamente oxidantes, como o $\mathrm{V}_{2} \mathrm{O}_{5}$ e o $\mathrm{FeOCl}$, produzem nanocompósitos onde a intercalação do monômero e sua polimerização oxidativa ocorrem simultaneamente. Este tipo de reação está limitada a hospedeiros que possuem um potencial
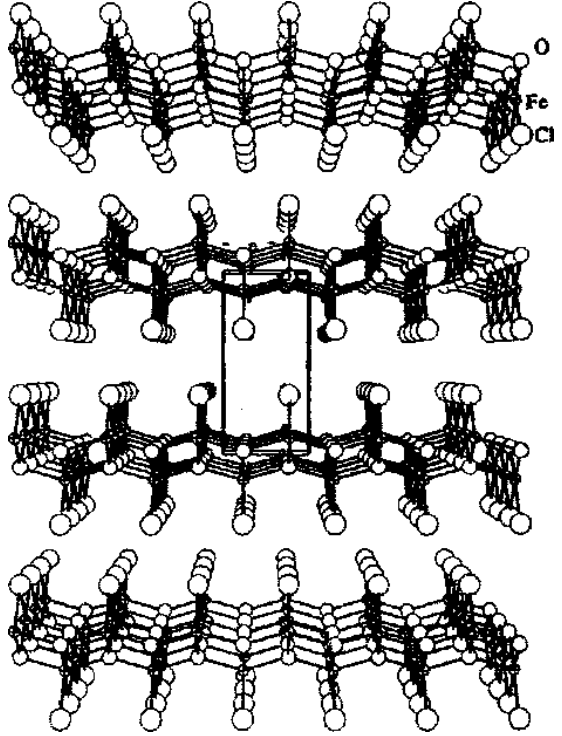

Figura 11. Estrutura lamelar do $\mathrm{FeOCl}^{132}$.

redox suficiente para oxidar o monômero, além de possuir uma estrutura que permita que o polímero seja realmente inserido entre as lamelas. Por outro lado, matrizes hospedeiras que não possuem o potencial redox adequado podem formar nanocompósitos de duas maneiras: i) através de modificações químicas anteriores, de modo a introduzir um agente oxidante forte na sua estrutura ou ii) pela introdução inicial do monômero, seguida de sua polimerização através de um agente externo.

$\mathrm{O} \mathrm{MoO}_{3}$, por exemplo, não possui potencial redox suficiente para polimerizar o pirrol ou a anilina. Desta maneira, Kerr e col. ${ }^{71}$ desenvolveram um método que envolve, em um primeiro estágio, um aumento do espaço interlamelar do hospedeiro. Isto é realizado através da redução do $\mathrm{MoO}_{3}$, com concomitante formação de óxidos do tipo $\left[\mathrm{Li}^{+}\left(\mathrm{H}_{2} \mathrm{O}\right)_{\mathrm{n}}\right]_{\mathrm{x}}\left[\mathrm{Na}^{+}\left(\mathrm{H}_{2} \mathrm{O}\right)_{\mathrm{m}}\right]_{\mathrm{y}}\left[\mathrm{MoO}_{3}\right]_{\mathrm{x}+\mathrm{y}}$ ou simplesmente $[\mathrm{Li} / \mathrm{Na}]_{0,25} \mathrm{MoO}_{3} \cdot \mathrm{H}_{2} \mathrm{O}$. Os cátions $\mathrm{Li}^{+}$e $\mathrm{Na}^{+}$ hidratados ocupam o espaço interlamelar do $\mathrm{MoO}_{3}$, causando uma maior separação entre as lamelas. A formação do nanocompósito foi realizada através da reação deste material com anilina, na presença de $\mathrm{FeCl}_{3}$, resultando em reações de troca iônica entre os cátions alcalinos interlamelares e a polianilina positivamente carregada, que é gerada pela reação da anilina com o $\mathrm{FeCl}_{3}{ }^{71}$. O nanocompósito obtido foi caracterizado como $[\mathrm{PAni}]_{0,24} \mathrm{MoO}_{3}$ e utilizado como cátodo em bateria de inserção de lítio, apresentando um rendimento muito superior ao observado para $\mathrm{O} \mathrm{MoO}_{3}$ puro.

Resultados interessantes também foram obtidos através da síntese da polianilina no espaço interlamelar do 2-carboxietilfosfonato de estanho IV (SnP-C) ${ }^{142-144}$. Numa etapa inicial, o hospedeiro em contato com uma solução ácida contendo $\mathrm{Fe}^{3+}$, sofre troca iônica tendo seus hidrogênios ácidos substituídos por íons $\mathrm{Fe}^{3+}$. $\mathrm{O} \mathrm{Fe}^{3+}$ na estrutura do hospedeiro atua como agente oxidante para a posterior polimerização da anilina, possibilitando a formação do polímero no espaço lamelar do SnPC (Figura 12). O nanocompósito foi caracterizado por FTIR, DRX e termogravimetria. A variação da distância interlamelar confirma a presença da PAni entre as lamelas do hospedeiro. Propriedades eletroquímicas características da polianilina foram observadas nos voltamogramas cíclicos através da presença de dois processos redox reversíveis bem definidos, relacionados às transições leucoesmeraldina $\leftrightarrow$ esmeraldina $\mathrm{e}$ esmeraldina $\leftrightarrow$ pernigranilina. A ausência de um terceiro par redox no voltamograma em potenciais intermediários é uma forte evidência do maior ordenamento das cadeias poliméricas, uma vez que, este processo redox intermediário está relacionado à reticulação do polímero ${ }^{145}$. Resultados similares também 
foram obtidos em nanocompósitos de $\alpha$-hidrogenofosfato de estanho (IV) e polianilina ${ }^{146}$.

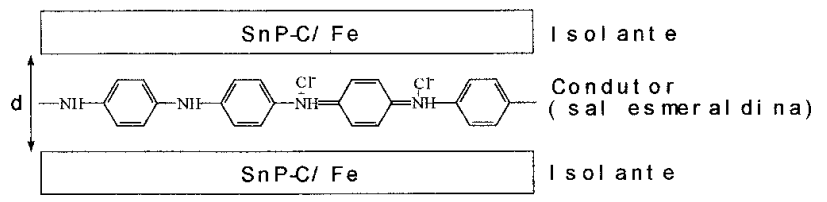

Figura 12. Esquema representando a formação da polianilina (no estado condutor) na lamela do hospedeiro $\mathrm{SnP-C}$, onde $d=$ espaço interlamelar ${ }^{144}$.

A morfologia do polímero determina a facilidade de transferência de carga no seu interior (bulk) e nas interfaces ${ }^{147}$. Há evidências que o aumento da ordem molecular e supramolecular intensificam as propriedades relacionadas com transporte iônico ${ }^{148,149}$ e eletrônico ${ }^{51,150}$ no polímero. De acordo com o modelo proposto por Micaroni e De Paoli ${ }^{151}$, a conversão de energia fotoeletroquímica em filmes de polímeros condutores depende do equilíbrio desses dois processos que ocorrem com cinéticas diferentes quando o sistema é irradiado. O comportamento fotoeletroquímico do nanocompósito PAni/SnP-C foi investigado e observou-se fotocorrente anódica ou catódica, dependendo da diferença de potencial aplicada (Figura 13) ${ }^{152}$. A fotocorrente obtida a partir deste compósito é comparável a valores descritos na literatura para filmes contendo somente polímeros condutores ${ }^{153-156}$. Assim, os valores determinados foram bastante satisfatórios considerando-se que a concentração de polímero intercalado (material fotoativo) não ultrapassa os $4 \% \mathrm{em}$ massa. A intensificação do efeito fotoeletroquímico foi atribuída, portanto, ao maior ordenamento das cadeias de polianilina, facilitando os processos de transporte de massa e transferência de carga.

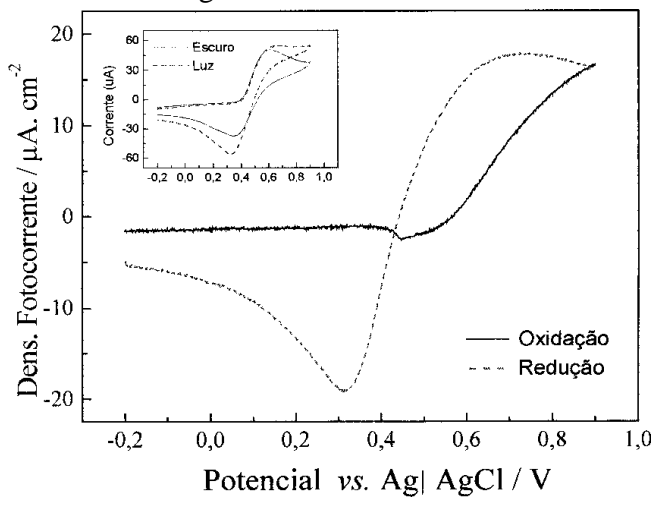

Figura 13. Resposta fotoeletroquímica do compósito PAni/SnP-C no eletrólito $\mathrm{HClO}_{4}$ 0,1 $\mathrm{M} / \mathrm{LiClO}_{4}$ 0,1 M, contendo o par redox $\mathrm{KI}$ 0,2 $\mathrm{mM} / \mathrm{I}_{2}$ 0,02 $\mathrm{mM}$; velocidade de varredura $5 \mathrm{mV} . \mathrm{s}^{-1}$. Em destaque, os voltamogramas obtidos com o sistema no escuro e sob irradiação ${ }^{152}$.

\section{MATRIZES HOSPEDEIRAS TRIDIMENSIONAIS}

Nos últimos 4 anos, Alves e cols..$^{73,157,158,159}$ desenvolveram uma metodologia de polimerização de pirrol e anilina nos poros de vidros porosos do tipo Vycor (PVG). Trata-se de um vidro altamente transparente à luz visível, formado basicamente por $\mathrm{SiO}_{2}$, contendo uma rede aleatória de poros tridimensionais interconectados ${ }^{160}$. A densidade de poros corresponde a $28 \%$ do volume total do material e o diâmetro destes poros é da ordem de $8 \mathrm{~nm}^{158}$. A superfície interna dos poros do PVG é formada por grupamentos ácidos $\mathrm{Si}-\mathrm{O}-\mathrm{H}^{161,162}$, que possibilitam a utilização deste material como trocador iônico. Uma representação esquemática da estrutura porosa do PVG está ilustrada na Figura 14.

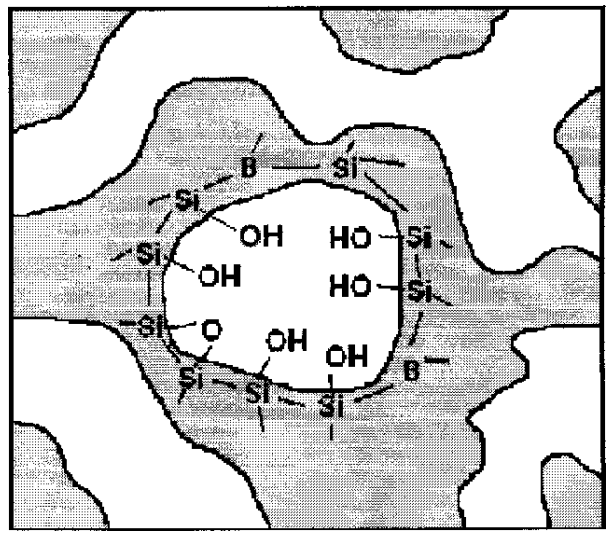

Figura 14. Representação esquemática da estrutura porosa do $P V G$. A parte escura corresponde à rede de sílica e a parte clara aos poros ${ }^{158}$.

A polimerização do pirrol no interior dos poros do PVG foi realizada por íons $\mathrm{Cu}^{2+}$, previamente incorporados à estrutura do vidro através de reações de troca iônica ${ }^{73,146,158}$. A cinética de polimerização do pirrol no interior do PVG foi acompanhada in situ por espectroscopia UV-Vis, indicando que o polímero começa a se formar com baixo grau de oxidação, tornando-se altamente oxidado (e portanto, condutor) após 30 minutos de reação. A formação do nanocompósito foi também confirmada por espectroscopia infravermelho e Raman. O resultado mais interessante, entretanto, foi obtido por ressonância magnética nuclear de ${ }^{13} \mathrm{C}$ no estado sólido com rotação no ângulo mágico e polarização cruzada (CP-MAS-NMR). Neste espectro obteve-se somente 2 picos estreitos, a 126 e 106 ppm, atribuídos aos átomos de carbono $\alpha$ e $\beta$ do anel pirrólico, Figura 15. A ausência total de outros picos e a similaridade do espectro obtido com o espectro do 2,5-dimetilpirrol indica que o PPi formado nos poros do PVG possui substituições somente nos átomos adjacentes ao átomo de nitrogênio, ou seja, um polímero sem reticulações e com uma estrutura linear ${ }^{73,158}$.

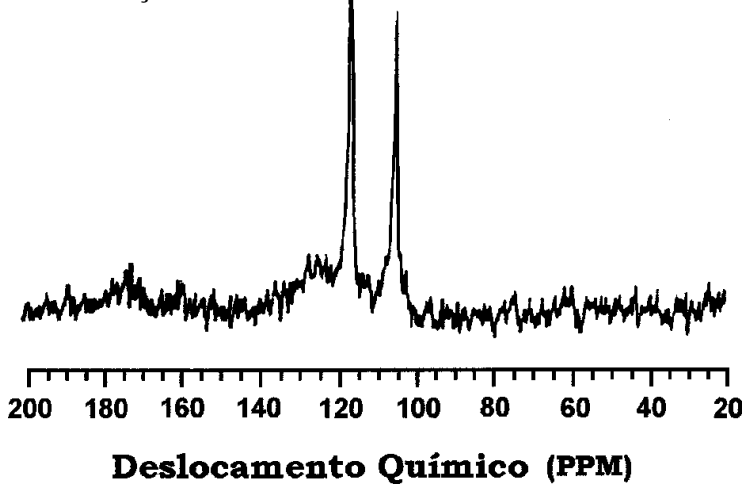

Figura 15. $R M N{ }^{13} \mathrm{C}$ do nanocompósito PVG/Polipirrol.

Os mesmos autores também utilizaram o PVG como matriz para a polimerização da anilina ${ }^{157,158}$. Neste caso, a anilina foi inicialmente incorporada ao vidro, através de reações com os grupamentos silanóis, e posteriormente oxidada com uma solução de $\left(\mathrm{NH}_{4}\right)_{2} \mathrm{~S}_{2} \mathrm{O}_{8}$. O nanocompósito formado é verde e altamente transparente. Análise por espectroscopias UV-Vis-IVP e Raman indicaram a formação da polianilina em sua forma condutora, sal esmeraldina. Verificou-se que o nanocompósito muda de cor com o $\mathrm{pH}$, (passando de verde escuro em $\mathrm{pH}=1$ para azul escuro em $\mathrm{pH}=13$ ), o que lhe confere a possibilidade de ser utilizado como sensor óptico de $\mathrm{pH}$. A Figura 16 representa a evolução do espectro Vis-IVP, em função do tempo, para o nanocompósito em contato com uma solução de $\mathrm{NH}_{4} \mathrm{OH}$, indicando o desaparecimento das bandas características do sal 
esmeraldina (774 e $412 \mathrm{~nm}$ ) e o surgimento das bandas relativas à base esmeraldina (561 e $320 \mathrm{~nm})$. Análise de microscopia eletrônica de transmissão revela a formação de filamentos de polianilina com $1,5 \mathrm{~nm}$ de espessura, dispersos pela matriz vítrea. A porção vítrea é solubilizada quando o nanocompósito é adicionado à solução de HF, e o polímero resultante apresentase na forma de bastões altamente organizados (Figura 17) ${ }^{157}$.

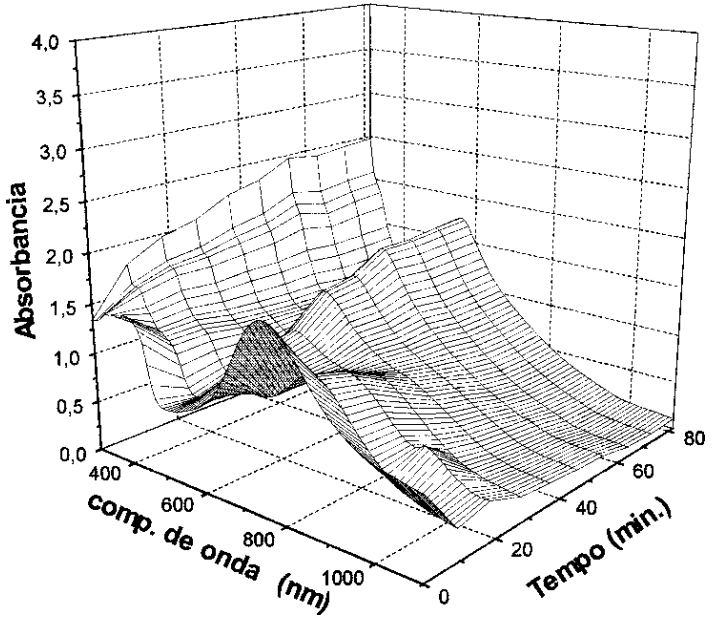

Figura 16. Evolução do espectro de absorção UV-Vis-NIR do nanocompósito PVG/PAni em uma solução $1 \mathrm{M}$ de $\mathrm{NH}_{4} \mathrm{OH}^{157-158}$.
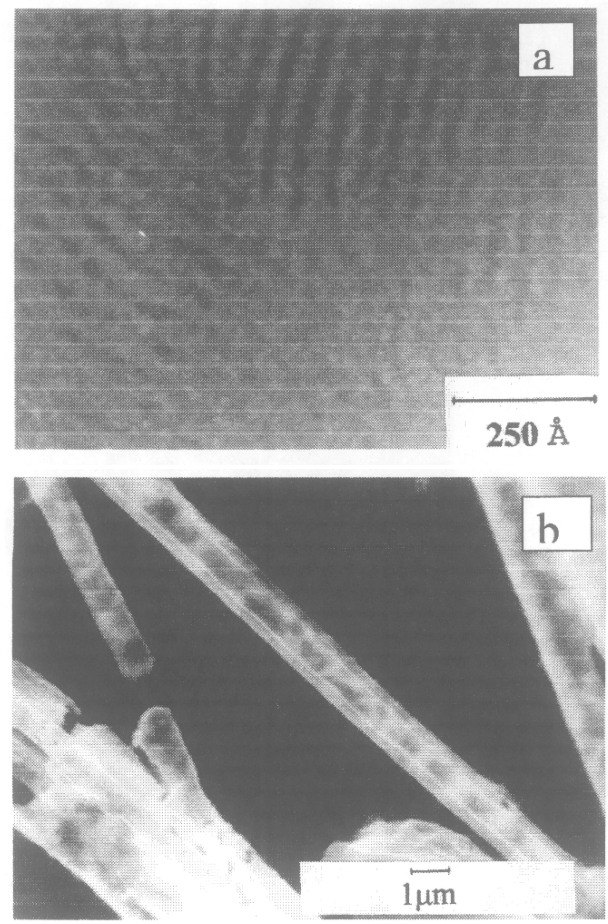

Figura 17. Micrografias eletrônicas de transmissão do nanocompósito PVG/polianilina (a) e da polianilina extraída do PVG com HF $48 \%(b)^{157}$.

Os nanocompósitos formados entre polianilina ou polipirrol e o PVG (distribuição de poros de 20 a $200 \AA$ ) mostraram-se extremamente interessantes, pois os polímeros são sintetizados em poros com diâmetros muito reduzidos, ordem de nanometros, originando verdadeiros "fios moleculares" dispersos aleatoriamente na rede vítrea. Além do mais, a alta homogeneidade e transparência dos nanocompósitos obtidos abrem perspectivas de potenciais aplicações para estes materiais.
Filmes de sílica também estão sendo utilizados como template para o crescimento de polímeros condutores. Malhotra e cols. ${ }^{163}$ sintetizaram eletroquimicamente a PAni no interior de filmes de sílica obtidos pelo método sol-gel a partir de tetraetil ortosilicato (TEOS) e contendo poros com diâmetro aproximado de $500 \AA$. A presença do polímero dentro da matriz de sílica foi confirmada por várias técnicas. A eletroatividade da PAni foi constatada através da variação do seu espectro de absorção em função do potencial aplicado. Nesta mesma direção, Neves e cols. ${ }^{164}$ obtiveram matrizes hospedeiras à base de sílica sintetizadas via processo sol-gel. A utilização de um agente reticulante, o 1,1,3,3tetrametildietoxidisiloxano (TMDES), conferiu às partículas de sílica uma morfologia globular que permitiu o crescimento das cadeias de PAni nos seus interstícios formando o compósito PAni/Silica sol-gel (Figura 18).
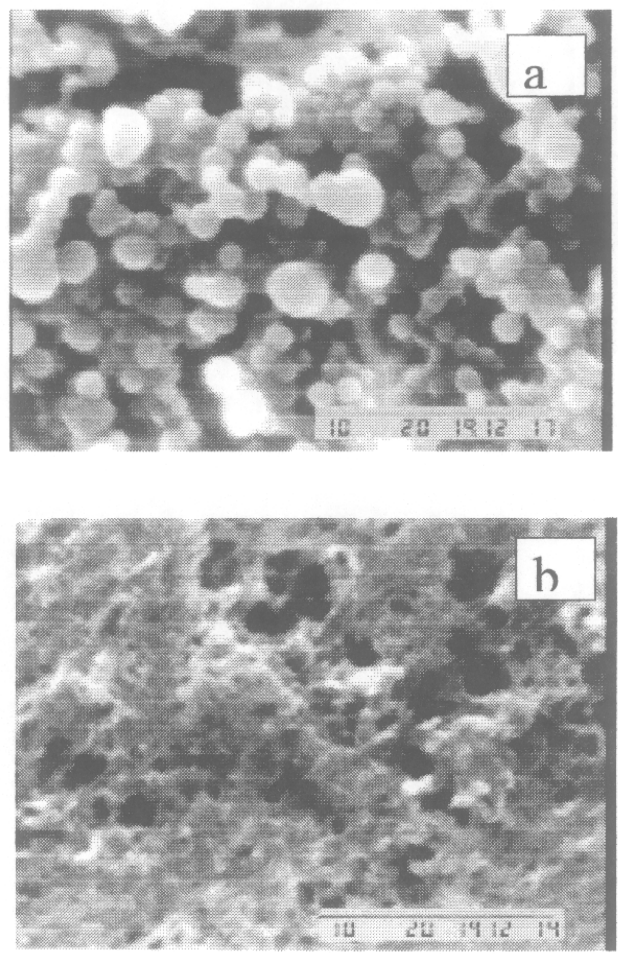

Figura 18. Micrografias eletrônicas de varredura da matriz de sílica sol-gel (a) e do compósito PAni/sílica sol-gel $(b)^{163}$.

Em 1991 De Paoli e cols. ${ }^{165}$ prepararam um compósito recobrindo a polianilina sintetizada eletroquimicamente com um filme de acetato de celulose (AC). As propriedades eletrocrômicas do filme PAni/AC foram estudadas e os resultados indicaram que o acetato de celulose não altera os processos redox e o eletrocromismo da polianilina. A membrana de acetato de celulose é constituída por uma rede de poros que diminuem de tamanho à medida que se aproxima da interface membrana/ substrato, Figura 19. O diâmetro desses poros varia entre 2 e $24 \mu \mathrm{m}$. As membranas foram utilizadas por Neves e De Paoli, como template na síntese da polianilina ${ }^{166}$. Três tipos de filmes foram analisados comparativamente: $i)$ PAni sintetizada galvanostaticamente sobre substrato de platina; ii) PAni sintetizada galvanostaticamente dentro dos poros de uma membrana de acetato de celulose depositada previamente sobre o substrato de platina e, iii) PAni na forma de pó, sintetizada quimicamente, suspensa em uma solução de acetato de celulose, coagulada posteriormente em água.

Segundo os autores, o crescimento da PAni nos poros da membrana pode ser acompanhado visualmente, uma vez que a 

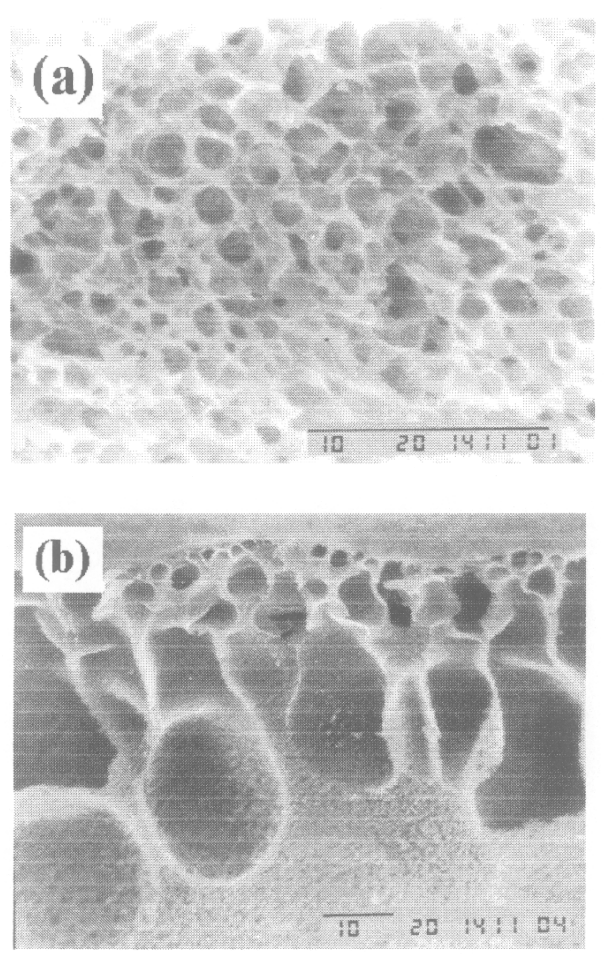

Figura 19. Microscopia eletrônica de varredura da membrana de acetato de celulose: (a) imagem da superfície, aumento de 1500x, (b) imagem da fratura, aumento de $3500 x^{165}$.

membrana passou gradativamente de transparente a verde cla$\mathrm{ra}^{166}$. Para confirmar a síntese da PAni no interior da matriz de acetato de celulose, foram feitas medidas de absorção UV-visível na região entre 200 e $900 \mathrm{~nm}$.

Ao contrário dos semicondutores cristalinos, os polímeros condutores não formam uma interface sólido/líquido bem definida numa cela eletroquímica. O filme polimérico fica intumescido com a solução do eletrólito, ocorrendo uma interação direta entre as cadeias do polímero e a solução. Assim, apesar do tamanho dos poros da membrana de acetato de celulose não ser pequeno o suficiente para impedir os processos de reticulação da polianilina, sua estrutura porosa permite facilmente o intumescimento do filme aumentando a área superficial do polímero exposta ao eletrólito. Consequentemente, os processos de transferência de carga e transporte de massa são intensificados. Esse comportamento fica fortemente evidenciado ao se comparar a resposta fotoeletroquímica dos filmes de PAni galv./AC (Figura 20c) com PAni pó/AC (Figura 20b). Os primeiros apresentaram uma fotocorrente até cinco vezes mais intensa em relação ao filme sintetizado diretamente sobre o eletrodo de trabalho (Figura 20a) ${ }^{166}$.

Cavidades zeolíticas também têm sido utilizadas para encapsular polímeros condutores. Neste caso, as dimensões das cavidades são suficientes para acomodar somente uma cadeia polimérica, ou seja, as cadeias poliméricas formadas no interior do espaço zeolítico não podem interagir umas com as outras.

A primeira descrição da obtenção de PPi como "fio molecular", no interior da zeólita Y e Mordenita, foi feita por Bein e Enzel, em $1989^{167}$. A zeólita Y é um alumino-silicato que contém uma estrutura tridimensional com janelas de diâmetros de 0,3 e $0,8 \mathrm{~nm}$. Sua cela unitária pode ser representada pela composição $\mathrm{Na}_{56} \mathrm{Al}_{56} \mathrm{Si}_{136} \mathrm{O}_{384}(\mathrm{NaY})^{167}$. A Mordenita possui canais pseudo-unidimensionais, cuja cela unitária pode ser representada por $\mathrm{Na}_{8} \mathrm{Al}_{8} \mathrm{Si}_{40} \mathrm{O}_{96}$.
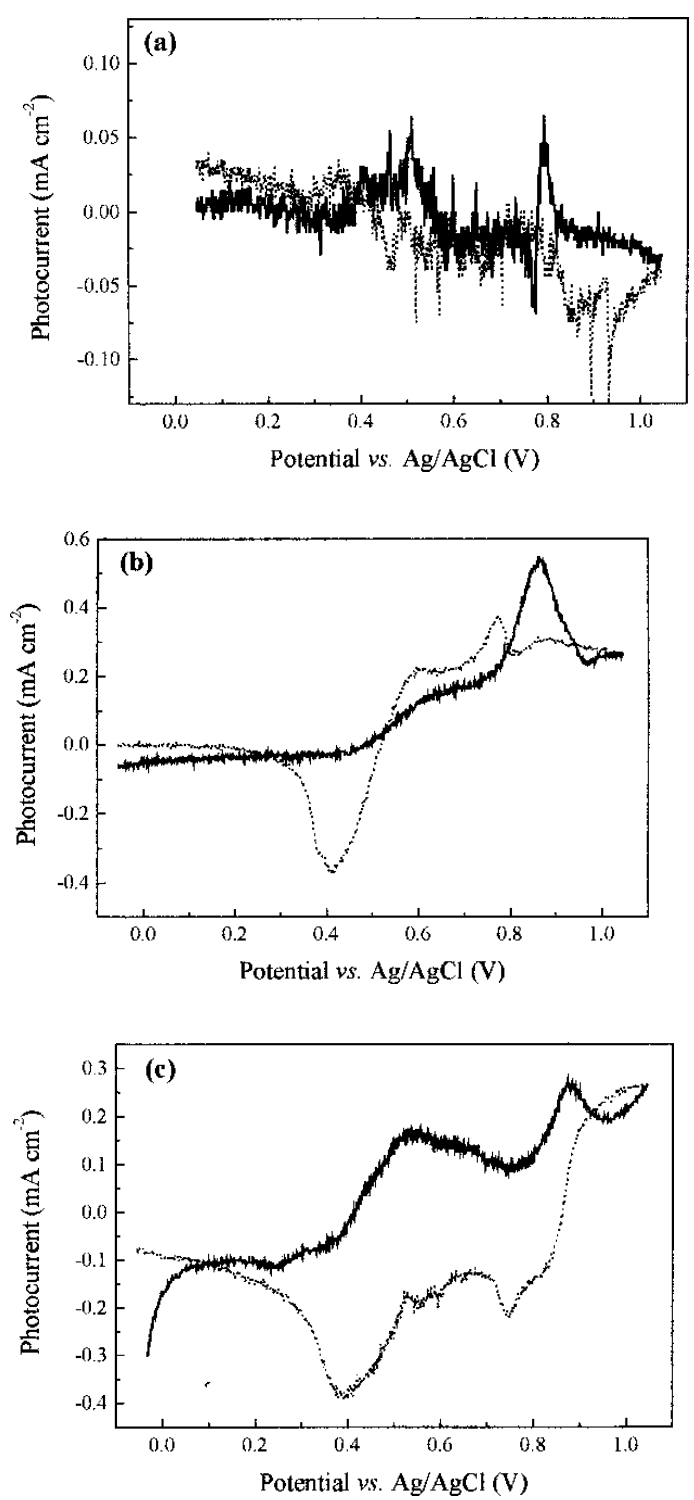

Figura 20. Resposta fotoeletroquímica apresentada pelos filmes de polianilina (a) e dos compósitos PAni/Ac (b) e PAni pó/Ac (c), durante os processos de oxidação (一) e redução (...) $)^{165}$.

A polimerização do pirrol nestas matrizes foi realizada através de íons $\mathrm{Cu}^{2+}$, utilizados como agente oxidante, que foram previamente trocados com os íons $\mathrm{Na}^{+}$presentes na zeólita. Esta zeólita modificada foi tratada com vapores de pirrol, que difundiram e polimerizaram-se no interior das cavidades. Tal processo pode ser visualizado de acordo com a representação abaixo (para a zeólita Y):

$\mathrm{NaY}+\mathrm{Cu}\left(\mathrm{NO}_{3}\right)_{2}$ (aq) $\stackrel{620 \mathrm{~K}}{\longrightarrow} \mathrm{Cu}_{\mathrm{x}}{ }^{\mathrm{II}} \mathrm{Na}_{\mathrm{z}} \mathrm{Y} \stackrel{\text { pi / vapor }}{\longrightarrow}$
$\mathrm{PPi} / \mathrm{Cu}_{\mathrm{x}}{ }^{\mathrm{I}} \mathrm{Na}_{\mathrm{z}} \mathrm{Y}$

A Figura 21 representa a formação de "fios moleculares" de PPi no interior das cavidades da zeólita Y. Uma vez, que os íons $\mathrm{Cu}^{2+}$ estão alocados no interior dos canais da zeólita, não há deposição do polímero na superfície externa do cristal. Isto foi confirmado por microscopia eletrônica de varredura e por medidas de condutividade. Como o polímero está incluído em uma matriz isolante, a condutividade do nanocompósito $\left(10^{-6} \mathrm{~S} . \mathrm{cm}^{-1}\right)$ mostra-se bastante inferior a do PPi puro $\left(1\right.$ a $\left.10 \mathrm{~S}^{-\mathrm{cm}^{-1}}\right)$. 


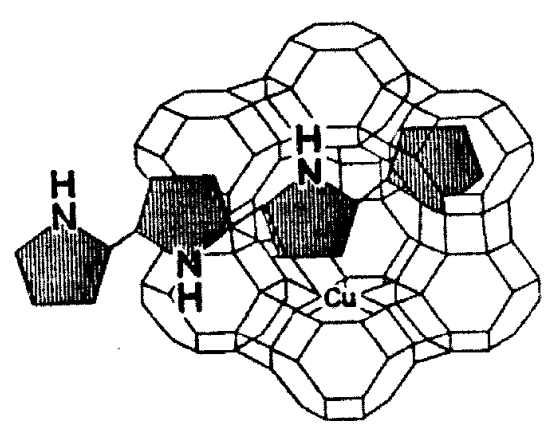

Figura 21. Estrutura de uma cadeia de polipirrol encapsulada na zeólita $Y^{166}$.

Utilizando o mesmo procedimento, também foram obtidos "fios moleculares" de politiofeno ${ }^{168}$ e polianilina ${ }^{169,170}$. No último caso foi utilizada a zeólita em sua forma ácida e a PAni foi obtida de acordo com o esquema abaixo: n-hexano/295K

$\mathrm{HY}+\mathrm{n} \mathrm{C}_{6} \mathrm{H}_{5} \mathrm{NH}_{2} \longrightarrow \mathrm{Y}\left(\mathrm{C}_{6} \mathrm{H}_{5} \mathrm{NH} 2\right)_{\mathrm{n}}$

$\mathrm{Y}\left(\mathrm{C}_{6} \mathrm{H}_{5} \mathrm{NH}_{3}\right) \mathrm{n}+\left(\mathrm{NH}_{4}\right)_{2} \mathrm{~S}_{2} \mathrm{O}_{8} \stackrel{\mathrm{H}_{2} \mathrm{O} / 273 \mathrm{~K}}{\longrightarrow} \mathrm{Y}(\mathrm{PAni})$

\section{CONCLUSÕES}

Um levantamento bibliográfico referente aos últimos 10 anos, deixa evidente que muitos esforços estão sendo dedicados na área de materiais ao trabalho com dimensões cada vez menores. Há uma tendência de "empurrar os limites" pesquisando-se desde nano a macromateriais e, neste sentido, o território dos nanomateriais ainda é particularmente desconhecido. Encontra-se também publicações que se referem a um número muito grande de materiais obtidos a partir de combinações de materiais mais simples: os chamados "(nano) compósitos". Vários (nano) compósitos têm propriedades muito superiores as dos seus constituintes devido às várias formas de sinergismo que estes podem apresentar.

Nesta revisão abordamos estes dois aspectos, enfocando os micro e nanocompósitos obtidos através da síntese template de polímeros condutores em matrizes sólidas hospedeiras. Este tema é bastante amplo e os exemplos considerados mais significativos foram apresentados, com o intuito de divulgar a potencialidade destes materiais. Com relação aos polímeros condutores, o benefício imediato da sua síntese em ambientes restritos é verificado no aumento significativo da condutividade, decorrente do maior ordenamento das cadeias poliméricas. No entanto, outras propriedades dependentes dos processos de transferência de carga e de transporte de massa podem ser intensificadas em função do aumento da ordem molecular dos polímeros. A investigação e compreensão destas propriedades é bastante recente, existindo ainda uma grande diversidade de aspectos a serem explorados.

Um ponto de vista que não foi discutido nesta revisão (e é pouco reportado na literatura) está relacionado com a melhoria das propriedades da matriz hospedeira com a presença do polímero condutor. Um exemplo recente e de grande interesse científico é a luminescência do silício poroso na região do visível $^{171,172}$. Estudos demonstram que a banda de luminescência observada no visível (região do vermelho-laranja) é devido à recombinação direta dos portadores nas nanoestruturas cristalinas do silício poroso ${ }^{173}$. Observa-se, no entanto, um decaimento da emissão óptica em função do tempo, atribuída à oxidação da superfície interna dos poros do silício ${ }^{174}$. Vários materiais foram testados como contato, porém a polianilina apresentou os melhores resultados por possuir uma janela de transmissão na região visível do espectro e baixa resistividade na forma condutora $^{175}$. Portanto, a presença do polímero condutor no compósito superou as limitações da matriz hospedeira, viabilizando a exploração de uma de suas propriedades.

A obtenção de (nano) compósitos nos moldes apresentados nesta revisão abre, ainda, a possibilidade de realização de um antigo desafio à comunidade científica, no que diz respeito à possibilidade de se combinar propriedades de compostos orgânicos e inorgânicos em um único material, formando materiais híbridos com propriedades ímpares. Além dos nanocompósitos citados, um grande número de outros materiais híbridos com estas características têm sido descrito na literatura, envolvendo os mais diferentes tipos de constituintes e as mais variadas possibilidades de aplicações. A síntese e estudo das propriedades de novos nanocompósitos é uma área recente e emergente, com perspectivas fascinantes no campo da ciência dos materiais.

\section{AGRADECIMENTOS}

Os autores agradecem o apoio financeiro e a bolsa de pósdoutorado da FAPESP (processo 97/03395-1) e ao PRONEX.

\section{REFERÊNCIAS}

1. Kanatzidis, M. G.; Chem. Eng. News 1990, 3 dez., 36

2. Shirakawa, H.; Ikeda, S.; Polymer 1971, 2, 231.

3. Shirakawa, H.; Ikeda, S.; J. Polymer Sci., Chem. 1974, 12, 929.

4. Shirakawa, H.; Louis, E. J.; MacDiarmid, A. G.; Chiang, C. K.; Heeger, A. J.; J. Chem. Soc.: Chem. Commun. 1977, 578.

5. Geniès, E. M.; Lapkowisk, M.; J. Electroanal. Chem. 1987, 220, 67.

6. Skotheim T. A.; Handbook of Conducting Polymers, Marcel Dekker, Nova Iorque, 1986.

7. Zoppi, R. A.; De Paoli, M. -A.; Quím. Nova 1993, 16, 560.

8. Wan, M.; Synth. Met. 1989, 31, 51.

9. Tan, K. L.; Tan, B. T. G.; Khor, S. H.; Neoh, K. G.; Kang, E. T.; J. Phys. Chem. Solids 1991, 52, 673.

10. Nalwa, H. S. Ed.; Handbook of Organic Conductive Molecules and Polymers; John Wiley \& Sons, Chichester, 1997.

11. MacDiarmid, A. G.; Epstein, A. J.; Anais do 2o. Congresso Brasileiro de Polímeros; São Paulo - SP 1989, 544.

12. Yu, G.; Cao, Y.; Andersson, M.; Gao, J.; Heeger, A. J.; Adv. Mater. 1998, 10, 385.

13. Strukelj, M.; Papadimitrakopoulos, F.; Miller, T. M.; Rothberg, L. J.; Science. 1995, 267, 1969.

14. Berggren, M.; Inganäs, O.; Gustafsson, G.; Rasmusson, J.; Andersson, M. R.; Hjertberg, T.; Wennerström, O.; Nature 1994, 372, 444.

15. Colvin, V. L.; Schlamp, M. C.; Alivisatos, A. P.; Nature 1994, 370, 354

16. Yamamoto, T.; Inoue, T.; Kanbara, T.; Jpn J. Appl. Phys. 1994, 33, L250.

17. Greenham, N. C.; Moratti, S. C.; Bradley, D. D. C.; Friend, R. H.; Holmes, A. B.; Nature 1993, 365, 628.

18. Grem, G.; Leditzky, G.; Ulrich, B.; Leising, G.; Adv. Mater. 1992, 4, 36 .

19. Heywang, G.; Jonas, F.; Adv. Mater. 1992, 4, 116.

20. Bigg, D. M.; Adv. Polym. Techn. 1984, 4, 255.

21. Tamamura, T.; Niwa, O.; Jpn. Kokai Tokkyo Koho JP 60, 228, 544, Apud Chem. Abstr. 1985, 104, 187766k.

22. Tamamura, T.; Niwa, O.; Jpn. Kokai Tokkyo Koho JP 60, 228, 544. Apud. Chem. Abstr. 1985, 104, 187766k.

23. Asanuma, T.; Takeda, J.; Jpn. Kokai Tokkyo Koho JP 61, 283, 656. Apud. Chem. Abstr. 1987, 107, 8599a.

24. Gazotti, W. A.; Casalbore-Miceli, G.; Geri, A.; De Paoli, M. -A.; Adv. Mater. 1998, 10, 60. 
25. Sapp, S. A.; Sotzing, G. A.; Reddiger, J. L.; Reynolds, J. R.; Adv. Mater. 1996, 8, 808.

26. Raistryck, I. D.; in Electrochemistry of Semiconductors and Electronics-Processes and Devices, MacHardy, J.; Ludwig, F., Eds., New Jersey, 1992.

27. Conway, B. E.; J. Electrochem. Soc. 1991, 138, 1539.

28. Geniès, E. M.; New J. Chem. 1991, 15, 373.

29. Li, F. B.; Albery, W. J.; J. Eletronal. Chem. 1991, 302, 279.

30. Roman, L. S.; Andersson, M.; Yohannes,T.; Inganas, O.; Adv. Mater. 1997, 9, 1164.

31. Sansiñena, J. M.; Olazábal, V.; Otero, T. F.; Polo da Fonseca, C. N.; De Paoli, M. A.; Chem. Commun. 1997, 2217.

32. Wung, C. J.; Wijekoon, W. M. K. P.; Prasad, P. N.; Polymer 1993, 34, 1174.

33. Wung, C. J.; Pang, Y.; Prasad, P. N.; Karasz, F. E.; Polymer 1991, 32, 605.

34. He, G. S.; Wung, C. J.; Xu, G. C.; Prasad, P. N.; Appl. Opt. 1991, 30, 3810.

35. Hsueh, C.; Brajter-Toth, A.; Anal. Chem. 1994, 66, 15.

36. Kuwabata, S.; Martin, C. R.; Anal. Chem. 1994, 66, 2757.

37. Gardner, J. W.; Bartlett, P. N.; Synth. Met. 1993, 57, 3665.

38. Hable, C. T.; Wrighton, M. S.; Langmuir 1993, 9, 3284.

39. Bull, R. A.; Fan, F. R.; Bard, A. J.; J. Electrochem. Soc. 1983, 130, 1636.

40. Kivelson, S.; Heeger, A. J.; Synth. Met. 1988, 22, 371.

41. Bredas, J. L;. Street, G. B.; Acc. Chem. Res. 1985, 18, 309.

42. Lei, J.; Cai, Z.; Martin, C. R.; Synth. Met. 1992, 46, 53.

43. MacDiarmid, A. G.; In Conjugated Polymers and Related Materials", Salaneck, W. R.; Lundstrom, I.; Ranby, B., Eds., Oxford University Press, Oxford, 1993, 73.

44. Fosong, W.; Jinsong, T.; Lixiang, W.; Hongfang, Z.; Zhishen, M.; Mol. Cryst. Liq. Cryst. 1988, 160, 175.

45. Naarmann, H.; Theophilou, N.; Synth. Met. 1987, 22, 1.

46. Miller, J. S.; Adv. Mater. 1993, 5, 587.

47. R. -Hitzky, E.; Aranda, P.; An. Quim. Int. Ed. 1997, 93, 197.

48. Dickey, F. H.; Proc. Natl. Acad. Sci. USA 1949, 35, 227.

49. Wu, C. G.; Bein, T.; Science 1994, 264, 1757.

50. A distinção entre "micro" e "nano" é ambígua. Martin definiu um nanocilindro como um cilindro com diâmetro de $100 \mathrm{~nm}(1000 \AA)$ ou menos.

51. Cai, Z.; Martin, C. R.; J. Am. Chem. Soc. 1989, 111, 4138.

52. Martin, C. R.; Adv. Mater. 1991, 3, 457.

53. Martin, C. R.; Van Dyke, L. S.; Cai, Z.; Liang, W.; J. Am. Chem. Soc. 1990, 112, 8976.

54. Martin, C. R.; Science 1994, 266, 1961.

55. Giannelis, E. P.; Adv. Mater. 1996, 8, 29.

56. Gehr, R. J.; Boyd, R. W.; Chem. Mater. 1996, 8, 1807.

57. Yang, P.; Lieber, C. N.; Science 1996, 273, 1836.

58. Hayashi, T.; Hirono, S.; Tomita, M.; Umemura, S.; Nature 1996, 381, 772 .

59. Ajayan, P. M.; Stepan, O.; Redlich, P.; Colliex,C.; Nature 1995, 375, 564.

60. Baral, S.; Schoen, P.; Chem. Mater. 1993, 5, 145.

61. Archibald, D. D.; Mann, S.; Nature 1993, 364, 430.

62. Shang, S. -Y.; Liu, L.; Asher, S. A.; J. Am. Chem. Soc. 1994, 116, 6739.

63. Riedel, R.; Kleeber, H. -J.; Schoefelder, H.; Aldinger, F.; Nature 1995, 374, 526.

64. Golden, H. H.; DiSalvo, F. J.; Frechet, J. M. J.; Silcox, J.; Thomas, M.; Elman, J.; Science 1996, 273, 782.

65. Douglas, T.; Dickson, D. P. E.; Betteridge, S.; Charnock, J.; Garner, C. D.; Mann, S.; Science 1996, 273.

66. Ozin, G. A.; Adv. Mater. 1992, 4, 612.

67. Mehrotra, V.; Keddie, J. L.; Miller, J. M.; Giannelis, E. P.; J. Non Cryst. Sol. 1991, 136, 97.

68. Liu, Y. J.; Kanatzidis, M. G.; Inorg. Chem. 1993, 32, 2989.

69. Mehrotra, V.; Giannelis, E. P.; Solid State Commun. 1992, $51,115$.
70. Prassidies, K.; Bell, C. J.; Dianoux, A. J.; Wu, C. G.; Kanatzidis M. G.; Physica B 1992, 181, 668.

71. Kerr, T. A.; Wu, H.; Nazar, L. F.; Chem. Mater. 1996 8, 2005.

72. Nishida, F.; Dunn, B.; Knobbe, E. T.; Fuqua, P. D.; Kaner, R. B.; Mattes B. R.; Mat. Res. Soc.; Symp. Proc. 1990, $180,747$.

73. Maia, D. J.; Zarbin, A. J. G.; Alves, O. L.; De Paoli M. -A.; Adv. Mater. 1995, 7, 792.

74. Natta, G.; Mazzanti, G.; Corradini, P.; Atti Accad. Naz. Lincei, Cl. Sci. Fis. Mat. Nat., Rend. 1958, 25, 3.

75. Letheby, H.; J. Am. Chem. 1862, 15, 161.

76. Meisel, S. L.; Johnson, G. C.; Hartough H. D.; J. Am. Chem. Soc. 1950, 27, 1910.

77. Angeli, A.; Gazz. Chim. Ital. 1916, 46, 279.

78. Nishio, K.; Fujimoto, M.; Yoshinaga, N.; Ando, O.; Ono, H.; Murayama, T.; J. Power Sources 1995, 56, 189.

79. MacDiarmid, A. G.; Heeger A. J.; Synth. Met. 1979, 1, 101.

80. Mattoso, L. C. H.; Quím. Nova 1996, 19, 388.

81. Huang, W. S.; Humphrey, B. D.; MacDiarmid, A. G.; J. Chem. Soc. Faraday Trans. I 1986, 82, 2385.

82. Huang, W. S.; MacDiarmid, A. G.; Epstein, A. J.; J. Chem. Soc. Chem. Commun. 1987, 1784.

83. Syed, A. A.; Dinesan, M. K.; Talanta 1991, 38, 815.

84. Tourillon, G.; Garnier, F.; J Electroanal. Chem. 1982. $135,173$.

85. Tourillon, G.; Garnier F.; J Phys. Chem. 1983, 87, 2289.

86. Tourillon, G.; Garnier, F.; J Electroanal. Chem. 1984, 161, 407.

87. Kaneto, K.; Kohno, Y.; Yoshino, K.; Inuishi, Y.; J. Chem. Soc. Chem. Commun. 1983, 382.

88. Kaneto, K.; Yoshino, K.; Inuishi, Y.; Jpn. J. Appl. Phys. 1982, L21, 567.

89. Mark, H. F.; Bikales, N. M.; Overberger, C. G.; Kroschwitz, J. I.; In Encyclopedia of Polymer Science and Engineering, 2o ed., John Wiley \& Sons, Nova Iorque, 1985.

90. Cai, Z.; Lei, J.; Liang, W.; Menon, V.; Martin, C.R.; Chem. Mater. 1991, 3, 960.

91. Aviran, A.; J. Am. Chem. Soc. 1988, 110, 5697.

92. Sailor, M. J.; Curtis, C. L.; Adv. Mater. 1994, 6, 688.

93. Roth, S.; Mahlrr, G.; Shen, Y.; Coter, F.; Synth. Met. 1989, 28, C815.

94. Bate, R. T.; Sci. Am. 1988, 258, 96.

95. Engeering a Small World: From Atomic Manipulation to Microfabrication, seção especial da Science 1991, 254, 1300.

96. Jewell, J. L.; Harbison, J. P.; Scherer, A.; Sci. Am. 1991, $265,86$.

97. Devoret, M. H.; Esteve, D.; Urbina, C.; Nature 1992, $360,547$.

98. Parthasarathy, R.; Martin, C. R.; Nature 1994, 369, 298.

99. Martin, C. R.; Parthasarathy, R. V.; Adv. Mater. 1995, 7, 487.

100. Gref, R.; Science 1994, 263, 1600.

101. Lawson, D. R.; Liang, W.; Martin, C. R.; Chem. Mater. 1993, 5, 400 .

102. Fleischer R. L., Price P. B. e Walker R. M., Nuclear Tracks in Solids, University of California Press Berkeley, CA, 1975.

103. Kesting, R. E.; In Synthetic Polymeric Membranes, John Wiley \& Sons, New York 1985.

104. Pusch, W.; Walch, A.; Angew. Chem. Int. Ed. Engl. 1982, $21,660$.

105. Despic, A.; Parkhutik, V. P.; In Modern Aspects of Electrochemistry, Bockris, J.O.; White, R. E.; Conway B. E., Eds., Plenum, New York, 1989, vol. 20, cap. 6.

106. AlMawiawi, D.; Coombs, N.; Moskovits, M.; J. Appl. Phys. 1991, 70, 4421.

107. Tonucci, R. J.; Justus, B. L.; Campillo, A. J.; Ford, C. E.; Science 1992, 258, 783. 
108. Beck, J. S.; J. Am. Chem. Soc. 1992, 114, 10834.

109. Douglas, K.; Devaud, G.; Clark, N. A.; Science 1992, 257, 642 .

110. Parthasarathy, R.; Martin, C. R.; Chem. Mater. 1994, 6, 1627.

111. Martin, C. R.; Parthasarathy, R.; Menon, V.; Synth. Met. 1993, 55-57, 1165.

112. Burford, R. P.; Tongnan, T.; J. Mater. Sci. 1991, 26, 3264.

113. Liang, W.; Martin, C. R.; J. Am. Chem. Soc. 1990, 112, 9666.

114. Lei, J.; Menon, V. P.; Martin, C. R.; Polym. Adv. Technol. 1992, 4, 124.

115. Menon, V. P.; Lei, J. T.; Martin, C. R.; Chem. Mater. 1996, 8, 2382.

116. Cai, Z.; Martin, C. R.; J. Electroanal. Chem. 1991, 300, 35.

117. Martin, C. R.; Acc. Chem. Res. 1995, 28, 61.

118. Wu, C. G.; Bein, T.; Chem. Mater. 1994, 6, 1109.

119. Kresge, C. T.; Leonowicz, M. E.; Roth, W. J.; Vartuli, J. C.; Beck, J. S.; Nature 1992, 359, 710.

120. Beck, J. S.; Vartuli, J. C.; Roth, W. J.; Leonowicz, M. E.; Kresge, C. T.; Schmitt, K. D.; Chu, C. T. -W.; Olson, D. H.; Sheppard, E. E.; McCullen, S. D.; Higgins, J. P.; Schlenker, J. L.; J. Am. Chem. Soc. 1992, 114, 10834.

121. Chen, C. -Y.; Li, H. -X.; Davis, M. E.; Microporous Mater. 1993, 2, 17.

122. Branton, P. J.; Hall, P. G.; Sing, K.S.W.; J. Chem. Soc., Chem. Commun. 1993, 1257.

123. Grün, M.; Kurganov, A. A.; Schacht S.; Schüth F.; Unger, K. K.; J. Chromatogr. A 1996, 740, 1.

124. Schüth, F.; Ber. Bunsenges. Phys. Chem. 1995, 99, 1306.

125. Beck, J. S.; Vartuli, J. C.; Kennedy, G. J.; Kresge, C. T.; Roth, W. J.; Schramm, S. E.; Chem. Mater. 1994, 6, 1816.

126. Kanatzidis, M. G.; Wu, C. G.; Marcy, H. O.; DeGroot, D. C.; Kannewurf, C. R.; Adv. Mater. 1990, 2, 364.

127. Liu, Y. J.; DeGroot, D. C.; Schindler, J. L.; Kannewurf, C. R.; Kanatzidis, M. G.; J. Chem. Soc., Chem. Commun. 1993, 593.

128. Kanatzidis, M. G.; Wu, C. G.; Marcy, H. O.; Kannewurf, C. R.; J. Am. Chem. Soc. 1989, 111, 4139.

129. Mehrotra, V.; Giannelis; E. P.; Solid State Commun. 1991, $77,155$.

130. Whittingham, M. S.; In Intercalation Chemistry: An Introduction, Academic Press, 1982.

131. Dines, M. B.; J. Chem. Educ. 1974, 51, 221.

132. Kanatzidis, M. G.; Tonge, L. M.; Marks, T. J.; Marcy, H.O.; Kannewurf, C. R.; J. Am. Chem. Soc. 1987, 109, 3797.

133. Kanatzidis, M. G.; Marcy, H. O.; McCarthy, W.J.; Kannewurf, C. R.; Marks, T. J.; Solid State Ionics 1989, 32/33, 594.

134. Wu, C. G.; DeGroot, D. C.; Marcy, H. O.; Schindler, J. L.; Kannewurf, C. R.; Bakas, T.; Papaefthymiou, V.; Hirpo, W.; Yesinowski, J. P.; Liu, Y. J.; Kanatzidis, M. G.; J. Am. Chem. Soc. 1995, 117, 9229.

135. Wu, C. G.; DeGroot, D. C.; Marcy, H. O.; Schindler, J. L.; Kannewurf, C. R.; Liu, Y. J.; Hirpo, W.; Kanatzidis, M. G.; Chem. Mater. 1996, 8, 1992.

136. Srinivasan, S.; Pramanik, P.; J. Mater. Sci. Lett. 1994, 13,365

137. Bissessur, R.; DeGroot, D. C.; Schindler, J. L.; Kannewurf, C. R.; Kanatzidis, M. G.; J. Chem. Soc. Chem. Commun. 1993, 687.

138. Chao, K. J.; Chang, T. C.; Ho, S. Y.; J. Mater. Chem. 1994, 4, 367.

139. Nakajima, H.; Matsubayashi, G.; Chem. Lett. 1993, 423. 140. Challier, T.; Slade, C. T.; J. Mater. Chem. 1994, 4, 367.
141. Kanatzidis, M. G.; Bissessur, R.; DeGroot, D. C.; Schindler, J. L.; Kannewurf, C. R.; Chem. Mater. 1993, 5, 595.

142. Maia, D. J.; Alves, O. L.; De Paoli, M. -A.; Synth. Met. 1997, 90, 37.

143. Medeiros, M. E., Alves, O. L.; J. Mater. Chem. 1992, 2,1075

144. Atkins, P. W.; In Physical Chemistry, Oxford University Press, London, 4a ed., 1990, 953.

145. Geniès, E. M.; Lapkowski, M.; Penneau, J. F.; J. Electroanal. Chem. 1988, $249,97$.

146. Zarbin, A. J. G.; Maia, D. J.; De Paoli, M. -A.; Alves, O. L.; Synth. Met. 1999, 102, 1277.

147. Penner, R. M.; Martin, C. R.; J Electrochem. Soc. 1986, $133,2206$.

148. Van Dyke, L. S.; Martin, C. R.; Synth. Met. 1990, 36, 275.

149. Van Dyke, L. S.; Martin, C. R.; Langmuir 1990, 6, 1118.

150. Cai, Z.; Lei, J.; Menon, V.; Martin, C. R.; Chem. Mater. 1991, 3, 457.

151. Micaroni, L.; De Paoli, M. -A.; Sol. Energy Mater. Sol. Cells 1996, 43, 79.

152. Maia, D. J.; Neves, S.; Alves, O. L.; De Paoli, M. -A.; Electrochem. Actan 1999, 44, 1945.

153. Kalaji, M.; Nyholn, L.; Peter, L. M.; Rudge, A. J.; J. Electroanal. Chem. 1991, 310, 113.

154. Li, Z.; Dong, S.; Electrochem. Acta 1991, 37, 1003.

155. El-Rashiedy, O. A.; Holdcroft, S.; J. Phys. Chem. 1996, 100, 5481.

156. Kilmartin, P. A.; Wright, G. A.; Electrochem. Acta 1996, $41,1677$.

157. Zarbin, A. J. G.; De Paoli, M. -A.; Alves, O. L.; Synth. Met. 1997, 84, 107.

158. Zarbin, A. J. G.; Tese de Doutorado, Instituto de Química, Unicamp, Campinas 1997.

159. Zarbin, A. J. G.; De Paoli, M. -A. e Alves, O. L.; Synth. Met. 1999, 99, 227.

160. Corning Glass Work; Mater. Eng. 1979, 90, 92.

161. Gafney, H. D.; Coord. Chem. Rev. 1990, 104, 113.

162. Gafney, H. D.; J. Macromol. Sci. Chem. 1990, A27, 1187.

163. Verhese, M. M.; Ramanathan, K.; Ashraf, S. M.; Kamalasanan, M. N.; Malhotra, B. D.; Chem. Mater. 1996, 8, 822 .

164. Neves, S.; Córdoba de Torresi, S. I.; Zoppi, R. A.; Synth. Met., no prelo.

165. De Paoli, M.- A.; Duek, E. R; Rodrigues, M. A.; Synth. Met. 1991, 41-43, 973.

166. Neves, S.; De Paoli, M. -A.; Synth. Met. 1998, 96, 49.

167. Bein, T.; Enzel, P.; Angew. Chem. Int. Ed. Engl. 1989, 28, 1962.

168. Enzel, P.; Bein, T.; J. Chem. Soc. Chem. Commun. 1989, 1326.

169. Bein, T.; Enzel, P.; Synth. Met. 1989, 29, E163.

170. Enzel, P.; Bein, T.; J. Phys. Chem. 1989, 93, 6270.

171. Halliday, D. P.; Holland, E. R.; Eggleston, J. M.; Adams, P. N.; Cox, S. E.; Monkman, A. P.; Thin Solid Films 1996, 276, 299.

172. Matveeva, E.; Parkhutik, V. P.; Diaz, K.; Calleja, R.; Martinez-Duarte, J. M.; J. Luminesc. 1993, 57, 175.

173. Nash, K. J.; Calcott, P. D. J.; Canham, L. T.; Kane, M. J.; Brumhead, D.; J. Luminesc. 1994, 60/61, 297.

174. Ito, T.; Hiraki, A.; J. Luminesc. 1993, 57, 331.

175. Lang, W.; Steiner, P.; Kozlowski, F.; J. Luminesc. 1993, 57,341 . 